\title{
Conducting perception research over the internet: a tutorial review
}

Andy T Woods, Carlos Velasco, Carmel A Levitan, Xiaoang Wan, Charles Spence

This article provides an overview of the recent literature on the use of internet-based testing to address important questions in perception research. Our goal is to provide a starting point for the perception researcher who is keen on assessing this tool for their own research goals. Internet-based testing undoubtedly has several advantages over in-lab research, including the ability to reach a relatively broad set of participants and to quickly and inexpensively collect large amounts of empirical data, via services such as Amazon's Mechanical Turk or Prolific Academic. In many cases, the quality of online data appears to match that collected in lab research. Generally-speaking, online participants tend to be more representative of the population at large than those recruited for lab based research. There are, though, some important caveats, when it comes to collecting data online. It is obviously much more difficult to control the exact parameters of stimulus presentation (such as display characteristics) in online research. There are also some thorny ethical elements that need to be considered by experimenters. Strengths and weaknesses of the online approach, relative to others, are highlighted, and recommendations made for those researchers who might be thinking about conducting their own studies using this increasingly-popular approach to research in the psychological sciences. 
Andy T. Woods ${ }^{1,2}$, Carlos Velasco ${ }^{1}$, Carmel A. Levitan ${ }^{3}$, Xiaoang Wan $^{4}$, \& Charles Spence ${ }^{1}$ (1)

1. Crossmodal Research Laboratory, Department of Experimental Psychology, University of Oxford, United Kingdom

2. Xperiment, Surrey, United Kingdom.

3. Department of Cognitive Science, Occidental College, Los Angeles, United States of America.

4. Tsinghua University, Beijing, China

DATE: JUNE 2015

WORD COUNT: 16,279 WORDS

SUBMITTED TO: PeerJ (MARCH, 2015)

CORRESPONDENCE TO: Dr. Andy Woods, Crossmodal Research Laboratory, Department of 24 Experimental Psychology, University of Oxford, Oxford OX1 3UD, UK; E-MAIL: andytwoods@gmail.com, TEL: +44 1865 271307; FAX: +44 1865310447. 
ABSTRACT

32 This article provides an overview of the recent literature on the use of internet-based testing to 33 address important questions in perception research. Our goal here is to provide a starting point for 34 the perception researcher who is keen on assessing this tool for their own research goals. Internet35 based testing undoubtedly has several advantages over in-lab research, including the ability to 36 reach a relatively broad set of participants and to quickly and inexpensively collect large amounts 37 of empirical data, via services such as Amazon's Mechanical Turk or Prolific Academic. In many 38 cases, the quality of online data appears to match that collected in lab-based research. Generally39 speaking, online participants tend to be more representative of the population at large than those 40 recruited for lab-based research. There are, though, some important caveats, when it comes to 41 collecting data online. It is obviously much more difficult to control the exact parameters of 42 stimulus presentation (such as display characteristics) in online research. There are also some 43 thorny ethical issues that need to be considered by the experimenter contemplating online research. 44 Strengths and weaknesses of the online approach, relative to others, are highlighted, and 45 recommendations made for those researchers who might be thinking about conducting their own 46 studies using this increasingly-popular approach to research in the psychological sciences. 
50 Over the last few years, the rapid growth of online research has revolutionized the way in which many experimental psychologists choose to conduct (at least some of) their research. On the one hand, it holds the promise of allowing the researcher to go well beyond the typical constraints of the Western, Educated, Industrialised, Rich, and Democratic (WEIRD, see Henrich et al., 2010) pools of participants who form the basis for the vast majority of psychological research. Internetbased testing also opens-up the possibility of conducting research cross-culturally (e.g., Knoeferle et al., 2015; Woods et al., 2013). Furthermore, the experience of many of those researchers who have started to work / publish in this area is that relatively large numbers of participants $(>100)$ can be collected in a comparatively short space of time (e.g., in less than $24 \mathrm{hrs,} \mathrm{and} \mathrm{often} \mathrm{in} \mathrm{less}$ than $1 \mathrm{hr}$ ) at relatively low cost (1-2 USD / participant / 10 minutes). Generally-speaking, such data collection can be achieved with relatively little effort on the part of the experimenters concerned.

On the downside, however, concerns have been expressed about the lack of control over certain factors, such as the inevitable lack of control over the precise parameters of stimulus presentation (for example, screen resolution / display characteristics), not to mention the lack of experimenter supervision of the participants while taking part in these studies. Another issue of concern is just how often supposedly anonymised data makes its way onto the web, whilst still containing details that can indirectly, and often directly, reveal the identity of the participant.

Nevertheless, despite these various concerns and limitations, there has been a rapid and dramatic growth in the number of studies that have been published using online testing over the last few years (see Figure 1). We argue that the far larger sample sizes that one typically attracts when engaged in online (as opposed to lab-based) testing, and the much broader diversity of such samples, can more than make up for many of the lacks of control that one is faced with as an experimenter. Indeed, conducting large-scale studies online, in combination with lab-based experiments offering finer control over the testing situation and stimuli, may be an attractive, not to mention economic strategy for a variety - or indeed perhaps the majority - of future psychological research in the area of perception. For the time being, though, such studies are limited to the delivery of visual and auditory stimuli. 
Target audience, and outline of the present article

82

In this article, our goal is to provide an up-to date overview of the pros and cons associated with conducting research online for those perception scientists who are considering supplementing their own lab-based research with this powerful new research methodology (for a general overview of online research for psychology researchers, see Gosling \& Mason, 2015). We have focused on present day issues that have mostly arisen since 2011. We flesh out some well-discussed issues in this article ourselves to provide a broad base for the interested reader and critically evaluate the challenges and benefits of online research. First, we highlight how much more representative of the population at large online participants are as compared to their lab-based counterparts, as well as how rapid and economical the collection of data can be online. Following on from this, we explore the various concerns that have been raised with regard to online research, focusing on timing-related issues and how the wide variety of hardware / software that may be used by one's participants can give rise to data problems. The common concern about the lack of supervision of the participants themselves is also dealt with. Although warranting a paper unto itself, we briefly touch on some of the ethical issues pertaining to online research. We also provide an overview of the main online testing platforms that are currently available to researchers. Finally, we end by drawing some general conclusions and highlighting what we see as the most promising opportunities for future research.

\section{Benefits of conducting research online}

Online research (conducted on a computer with access to the internet), has a number of potential benefits over more traditional lab-based studies, which will be evaluated in this section (our focus is primarily computer-based research, but we briefly mention smartphones in a later section). In particular, we discuss how online research can profit from more representative and diverse samples of participants, as well as the more efficient collection of large amounts of data, and simpler participant payments. 


\section{Easy access to large pools of participants}

108 One of the most important advantages associated with conducting online research is the speed and ease with which large amounts of data can be collected. In lab-based experiments, researchers

110 typically test participants individually or in small groups over a period of several days, weeks, or 111 even months. Unfortunately, this in-person testing of participants can introduce noise, attributable 112 to, for instance, differences in the way in which the task is explained (though see the article by 113 Mirams, Poliakoff, Brown, \& Lloyd, 2013, where the researchers attempted to avoid this issue by, 114 amongst other things, making sure that each participant received their instruction by means of an 115 audio-recording) or even basic demographic differences can influence performance on 116 psychological tasks (e.g., Marx \& Goff, 2005; Rumenik, Capasso, \& Henrick, 1977). Perhaps most 117 pertinently, research assistants / researchers can provide subtle unintentional cues to the 118 participants regarding how to respond to the task at hand (e.g., see Doyen, Klein, Pichon, \& 119 Cleeremans, 2012; Intons-Peterson, 1983; Orne, 1962). As Orne noted a little over half a century 120 ago, there is a social psychological element to any in-lab psychology study (perhaps surprisingly, 121 this has not received much attention in recent years). Furthermore, the scheduling of participants 122 takes time, and depending on the specific participant pool, there may be a significant number of 123 participants who do not turn up or else who turn up late to their appointed experimental session. 124 That said, paid for tools such as SonaSystems and Experimetrix nowadays help by automating 125 much of the sign-up process and can also send out reminder emails (https://www.sona126 systems.com/, http://www.experimetrix.com/; see also the soon to be released open source 127 LabMan toolbox, https://github.com/TheHandLaboratory/LabMan/). Another drawback of much 128 of the lab-based research is that it can be difficult to run multiple participants in parallel, because 129 of experimenter constraints, as well as limits on experimental set-ups / space.

130 By contrast, with online research, when utilizing the appropriate recruitment platform (the focus 131 of the next section), massive numbers of people can undertake a study at any time. What is more, 132 the availability of participants is not limited by the vagaries of the academic year, with participation 133 in many university settings being much more prevalent in term time than out of term time 134 (unfortunately compounding this issue, students who receive course credit as opposed to payment 135 for taking part in studies are both less motivated and have been shown to display less sustained 136 attention at the end of the term as compared to the start, Nicholls, Loveless, Thomas, Loetscher, $137 \&$ Churches, 2015). Note that outside of term time there are more individuals participating in 
138 studies online, which in all likelihood correlates with an increased number of students looking to 139 earn some money (LaPlante, personal communication, March 18, 2015). There can also be severe 140 challenges associated with scaling up one's sample sizes in the lab-setting, whereas online, the 141 pool of potential participants would appear to be more than large enough to adequately address 142 most questions (Mason \& Suri, 2012). Another practical benefit of conducting research online is 143 that the payment of participants can often be automated; that is, the researcher need only make one 144 payment instead of many, and does not need to collect hundreds of individual receipts from 145 participants, minimising their interaction with their financial department.

\section{Recruitment platforms}

148 There are several online resources for the recruitment of participants online, with perhaps the most 149 well-known being Mechanical Turk (MTurk; we detail some of the characteristics of platforms 150 popularly used for behavioural research in Table 1; for an overview of this platform from the New

151 Yorker, do watch this recent video http://www.newyorker.com/culture/culture-desk/video152 turking-for-respect). Although this platform is primarily aimed at letting those working in industry 153 recruit many individuals to do tasks related to business such as categorising photos or rating 154 website content (see also CloudCrowd, Innocentive, MicroWorkers and oDesk; Chandler et al., 155 2013; as well as Peer, Samat, Brandimarte \& Acquisti, 2015, on how good some of these sites are 156 when it comes to conducting behavioural research), the last few years have seen an increasing 157 number of psychological studies starting to use the service (e.g., Crump et al., 2013; perhaps $<5 \%$ 158 of MTurk usage is academic-related, Sheehan 2015). In 2014, Mechanical Turk claimed to have 159 half a million individuals registered (Paolacci \& Chandler, 2014; http://demographics.mturk160 tracker.com provides a live feed of several MTurk demographic characteristics). However, more 161 recent research suggests that the active potential (US) participants available for a typical study are 162 more likely to number only ten thousand (Stewart, Ungemach, Harris, Bartels, \& Newell, 163 submitted). Unfortunately, in the summer of 2014, Mechanical Turk stopped allowing new 164 'requesters' (individuals wanting others to complete a task), and new 'workers' in 2012 165 (participants), to sign-up who did not have sufficient credentials identifying them as residing in 166 the United States ${ }^{1}$, such as US bank accounts and Social Security Numbers (do see

\footnotetext{
${ }^{1}$ Although the reasons for this are still unknown, a first wave cull in 2012 had been thought to be due issues of fraud
} 
167 http://ai.reddit.com/r/mturk/\#ai, for some personal testimonials on the issue). Consequently, many 168 researchers, including ourselves, have begun to explore alternatives to Mechanical Turk (or rely 169 on third-party tools such as www.mTurkData.com, to continue having access to the platform). One 170 alternative service aimed specifically at academic research is Prolific Academic 171 (https://prolificacademic.co.uk/), which, as of January 2015, had just over 5000 people signed up

172 to take part in research, with just under 1000 new recruits signing up each month.

173 Besides providing a ready source of participants, recruitment platforms also let researchers recruit

174 from specific sub-populations. With Mechanical Turk, for example, researchers can specify 175 whether they wish to recruit participants just from the US, or from several countries, or from 176 anywhere in the world (permitting that there are MTurkers from those countries; one of us 177 attempted to collect data from workers in Mexico in 2013 and failed to get participants despite 178 posting a hit with a relatively generous payment rate). Going one step further, Prolific Academic 179 lets researchers specify a range of criteria for recruitment, such as native language, age, sex, and 180 even ethnicity.

181 Unfortunately, as alluded to before, one limitation with the existing platforms is that there is little 182 variability in terms of the country from which one can recruit. For example, in 2010, 47\% of 183 MTurkers were North American and 34\% from India (Paolacci, et al., 2010). It is no surprise that 184 given the aforementioned new sign-up policy for MTurk, the percentage of US Americans taking 185 part in recent years has become much larger (87\%, Lakkaraju, 2015). Prolific Academic, on the 186 other hand, has no such demographic blockade, with, as of 7/11/2014, participants predominately 187 coming from the US, UK, Ireland, and India $(42 \%, 33 \%, 4 \%$, and $2 \%$ respectively; 188 https://prolificacademic.co.uk/about/pool; note though, that individuals without an academic email 189 address could only sign-up as from a few months ago; visit

190 https://prolificacademic.co.uk/demographics for a live feed of demographic information pertaining 191 to this platform's participants). It would seem likely that the list of represented countries will grow 192 as the platform continues to expand.

193 - Table 1 about here-

regarding unscrupulous MTurkers gaming the system (Admin, 2013). It is the first author's belief, though, that the 2014 change occurred as pressure had been put on MTurk to ensure all its workers were tax identifiable. 
196 It is important to note that large swathes of potential participants from around the world still remain 197 untapped! How would one go about recruiting participants from China, for instance, or from

198 Colombia? Whilst sites such as TestMyBrain.org demonstrate that it is possible to recruit large 199 numbers of participants from English-speaking countries (76\%) via social networking sites and 200 search engines (e.g., $\mathrm{n}=4080$, in Germine et al.'s, 2012, first study), it is much harder to directly 201 recruit only from specific countries. One option here is to create your own research panel and 202 recruit people via the local / social media (e.g., Wilson, Gosling, \& Graham, 2012). A whole range 203 of commercial software solutions exists for such a purpose; unfortunately, we are not aware of any 204 open source alternatives (instead, some of us have developed our own, 205 https://github.com/ContributeToScience/participant-booking-app).

\section{Access to a more representative sample of participants}

208 Online research is less affected by sampling from pools of participants who can be categorized as WEIRD (Henrich et al., 2010) than traditional lab-based research (e.g., Behrend et al., 2011; Berinsky et al., 2012; Chandler et al., 2014; Goodman et al., 2013). So what is known about the

211 characteristics of online recruits? In terms of demographics, the ratio of female to male participants

212 is approximately matched and the average age of the participants is currently estimated to be 213 around 30 years of age (as found in several recent large-sampled online-studies; see Table 2 for a 214 summary). The distribution of ages is typically ex-Gaussian (as often seen with reaction time data; 215 Mason \& Suri, 2012). Figure 2 demonstrates this right-sided long-tailed distribution from one of 216 our own recent online studies (Woods et al., in prep). Here it is worth noting that one consequence 217 of the much broader range of ages targeted by online research is that it makes it easier to collect 218 data from older participants (as opposed to having to, for example, advertise in the local media for 219 older participants as is often required in lab-based studies). 
223 In terms of their ethnicity, Berinsky et al. (2012) contrasted US participants recruited through 224 Amazon's Mechanical Turk (MTurk; a popular platform for recruiting participants online) with a 225 sample purported to closely match the US population at large (Mathew, Krosnick, \& Arthur, 2010).

226 These researchers found that $83.5 \%$ of the Mechanical Turkers (MTurkers) were white (versus $22783.0 \%$ from the general population), 4.4\% were Black (versus 8.9\%) and 6.7\% were Hispanic 228 (versus 5\%; for interested readers, the authors also compared other differences such as marital 229 status, income, housing state and religion and found some between-groups variations). Not 230 restricting themselves to North Americans, Paolacci, Chandler, and Ipeirotis (2010) found that $23147 \%$ of MTurkers, recruited over a 3-week period in February, 2010, were from the US and 34\% 232 from India. As a side note, see Milland (2014b) for a thought-provoking account on some of the 233 hurdles faced by those outside of the US trying to earn a living via MTurk.

237 It is important to recognize that online participants might also have their own peculiarities. So, for example, Paolacci and Chandler (2014) have recently highlighted how, as a group, MTurkers are typically more computer literate, better educated, and less likely to be employed than the regular population; indeed, the authors argue that it is just such differences in computer literacy that may drive some of the key differences between the online participants and the population at large (Shapiro et al., 2013). Perhaps fitting with this 'geek' stereotype, Mason and Suri (2012) found that MTurkers tend to be less extraverted and less emotionally stable than those recruited from off the street, whilst also being more open to new experiences. The authors also reported that over half of the participants whom they tested reported being on a relatively low wage $(\leq 30,000$ USD). Goodman et al. (2012) directly tested how participants recruited through Mechanical Turk differed in the United States. No discernible difference was found between the groups in terms of their age, sex, or level of education. However, $27.5 \%$ of the MTurkers had English as their second language as compared to just $10.5 \%$ of those recruited from the street. The prevalence of self-reported clinical conditions such as depression matched that seen in the general population (Shapiro et al., 2013), and 95.5\% of MTurkers started some form of college education (Martire \& Watkins, 2015). 
253 Thus, despite the above-mentioned variations from the general population, online participants 254 seem to be more representative of the population at large than those typically recruited for lab255 based studies, in that a broader age range, and a more equal distribution of males and females, sign 256 up to take part in studies, who would appear to be equally susceptible to clinical conditions such 257 as depression (which has been shown to impact on perceptual processing, Fitzgerald, 2013), but 258 may be more educated than others in their offline community.

259 Here, it is also worth asking, whether online participants might not be WEIRD enough to 260 successfully complete studies? Could it be, for example, that those with too little research 261 experience respond haphazardly, thus distorting the pattern of results that is obtained? Not so, at 262 least not according to Chandler, Mueller, and Paolacci, (2014). These researchers found that over 263132 experiments, 16,408 participants had undertaken an average of 2.24 studies (standard 264 deviation of 3.19), with participants actually likely having taken part in tens or even hundreds of 265 studies. Indeed, Rand et al (2014) explicitly asked 291 MTurkers how many studies they had taken 266 part in, and found that the median worker had participated in approximately 300 scientific studies 267 (20 in the previous week; n.b. some MTurkers actively avoid academic research, LaPlante \& 268 Milland, personal communication, March 18, 2015) compared to 15 studies as self-reported by 269118 students as part of a participant pool in Harvard (one in the previous week).

270 So rather than potentially impacting results due to participant naivety, the results of research 271 conducted online may instead be skewed because of participant overfamiliarity. Indeed, the 272 repercussions of conducting many studies throughout the day has led to a discussion about whether 273 certain MTurkers may not end up becoming rather 'robotic' in their responding (Marder, 2015). It

274 is likely though that the field of perceptual psychology that focuses on the more automatic features 275 of the human brain, would be less affected by such issues as compared to more cognitive fields of 276 psychology. A recent article by the Washington Post (Searles \& Ryan, 2015) nicely summarises 277 this issue and other hot issues in the media at the moment that pertain to MTurk weirdness, and 278 likewise conclude (amongst other things) that the source from where participants are recruited is 279 not always critical. Another topic of concern is the high dropout rate that is sometimes exhibited 280 by online studies (e.g., Crump et al., 2013). Here the interested reader is directed to Marder's 281 (2015) excellent article on the topic of familiarity. 
282 It is not surprising that a variety of forums and online tools have arisen to help those taking part in 283 online research (especially on Mechanical Turk) and one concern is that online experiments and 284 their presumed goals are a focus of discussion via these tools (note that on some forums such as 285 MTurkGrind, reddit.com/r/mturk, and TurkerNation, such comments are quickly reported to 286 moderators and deleted, LaPlante \& Milland, personal communication, March 18, 2015). 287 However, according to Chandler, Mueller, and Paolacci (2014), whilst $28 \%$ of their 300 288 participants reported visiting Mechanical Turk orientated forums and blogs, it was the amount a 289 task paid (ranked as most important) and its duration (ranked second most important) that were 290 discussed most often as compared to, for example, a task's purpose (which was ranked sixth).

291 One can wonder what the impact would be of an experimenter recruiting through their own social 292 media channels or their lab websites, as it is likely that people similar to the experimenter are the 293 ones likely to undertake a study so advertised (a phenomenon known as homophily, e.g., Aiello et 294 al., 2012). Indeed, in January 2015, the Pew Research Center reported a range of substantial 295 differences of opinion between the North American public at large and their scientific community, 296 ranging from issues pertaining to eating genetically modified foods (88\% scientists in favour, 297 versus $37 \%$ of the general public), that humans have indeed evolved over time ( $98 \%$ versus $65 \%$ ) 298 and that climate change is mostly attributable to human activity ( $87 \%$ versus $50 \%)$. In some sense, 299 then, one might want to consider whether we scientists might actually not be the WEIRDest of

300 them all? Unfortunately we are not aware of any literature exploring this topic, but one needs only 301 to turn one's attention to Henrich et al.'s discussion of WEIRD participants (2010) for related 302 evidence as to the impact of such issues.

303 In summary, although online participants most certainly have their own peculiarities as compared 304 with the (typically American) population at large, it is doubtful whether this WEIRDness is any 305 more pronounced than that shown by the undergraduates who take part in our lab-based research.

306 The very fact that classical studies have been successfully replicated in both groups, each with 307 their own peculiarities, is actually reassuring in itself.

\section{Speed of data collection}

309 As online research is typically conducted in parallel, a large number of participants can be recruited 310 and take part in a study in a short space of time. With Mechanical Turk, for example, 100s of 
311 participants can sign up to take part within just 15 minutes of publicly releasing a study, as shown

312 from one of our recent studies (see Figure 3; Pechey, Attwood, Munafo, Scott-Samuel, Woods \&

313 Marteau, in prep). The obvious benefit is the ability to rapidly explore a given scientific issue, as

314 demonstrated by the 'what colour is that dress' viral, and Tarja Peromaa's admiral effort of

315 collecting data from 884 participants within a few days of 'that dress' going public (Peromaa,

316 2015). As pointed out by a reviewer, do bear in mind that significant effort may still be required

317 to link up with participant-providing services before data collection can commence. For example,

318 it may only take 10 minutes to set oneself up with a Mechanical Turk account if one uses software

319 that can automatically post experiments to this platform (see Table 3). If such software is not used,

320 however, it can take several days to familiarise oneself with the platform in order to conduct studies

321 manually. It may also take several weeks to create a study with an unfamiliar research software

322 package for the first time (see Table 3). And do bear in mind that it is also important that you are

323 on-hand to promptly answer any questions from your participants whilst the study is running

324 (typically $0-5 \%$ of our participants email us questions).

325

326

-Figure 3 about here-

327

328 Another benefit of the rapid collection of data is that it allows the researcher to explore the impact 329 of day-based events, such as Valentine's Day, Christmas, or Ramadan. Indeed, as 100s of 330 participants can be tested in less than an hour, this opens up the opportunity of testing individuals on even finer-grained timescales. Naturally, global time differences come into their own with such rapid sign-up.

333 Of course, one important caveat with the rapid large-scale sign-up of participants is that if there 334 happens to be a flaw in one's study, the experimenter could potentially (and rightly) receive 335 hundreds of angry emails, each of which often require individual attention (failure to do so in the 336 past has led to some researchers being blacklisted en-masse by MTurkers; Milland, personal 337 communication, March 18, 2015). Not only should the experiment work flawlessly with no 338 ambiguity in terms of the instructions given (as there are no experimenters present to clarify the 339 situation), the server-hardware running the study also needs to be up to scratch. From our own 340 experience with the first author's Xperiment research platform (http:/www.xperiment.mobi), our 
341 first studies were run from a basic Amazon Cloud server (t1.micro; see 342 https://aws.amazon.com/ec2/previous-generation/), assuming that it could meet the demands 343 thrown at it. However, we had not expected the sheer volume of requests to the server for one 344 particularly demanding video-streaming study, which caused the server to crash. We now run our 345 studies from a more substantial server (m1.small), and are in the process of providing our 346 participants with a live public messaging tool to contact the experimenter regarding any vagaries 347 of experimental design. Needless to say, it is particularly important with online research to pilot 348 one's study on several systems (perhaps with your colleagues) before releasing it to the online 349 community. Indeed, if the study is to be done on MTurk, be advised that the platform provides a 350 'testing ground' on which you can do your own experiments, and ensure that MTurk and your 351 software are properly communicating (https://requester.mturk.com/developer/sandbox). We also 352 suggest gradually increasing the required sample size of one's early studies (perhaps testing 10 353 participants with a study, then 50, then...) to ensure that the equipment can deal with demand.

\section{Economical}

355 In general, collecting data from participants online provides an economical means of conducting 356 research, with, for example, the experimenter not having to cover the fees sometimes associated 357 with participants travelling to and from the lab. Those who have looked at whether the payment 358 amount influences how many people are willing to take part (i.e., how many sign-up) and / or how 359 seriously they take the experiment (discussed later in the section entitled '5) Random responding')

360 have, perhaps somewhat surprisingly, shown little relation between reward and effort; only the 361 rate of recruitment seems to be influenced by payment size (Paolacci \& Chandler, 2014; Mason \& 362 Watts, 2009; though do see Ho, Slivkins, Suri, \& Vaughan, 2015, who show that bonuses can 363 sometimes improve task performance). A different picture emerges however, when you ask 364 MTurkers themselves what motivates people to take part in low wage research. In an excellent 365 blog article, Spamgirl, aka Kristy Milland (2014a), highlights how low wage tasks will tend to be 366 avoided by all, except by, for example, those using 'bots' to help automate their answers, and those 367 in a desperate situation - which very likely impacts on data quality (see also Silberman, Milland, 368 LaPlante, Ross, \& Irani, 2015).

369 We would argue that there is most certainly responsibility on the side of the experimenter to ensure 370 fair payment ${ }^{2}$ for work done, there being no minimum wage on, for example, Mechanical Turk 
371 (see the guidelines written by MTurkers themselves for conducting research on this platform, 372 http://guidelines.wearedynamo.org/). A sensible approach to payment may be to establish what the 373 participant would fairly earn for an hour-long study and then scale the payment according to task

374 duration. For example, Ipeirotis (2010) reported paying participants $\$ 1$ for a 12.5 minute study 375 (\$4.80 / hour) and Berinsky et al. (2012) \$6 / hour. An online discussion by MTurkers themselves 376 suggests that 10 cents / minute as a minimum going rate (Iddemonofelru, 2014); do note that this 377 is below the current minimum wage in the US, which is $\$ 7.25$ per hour, and 10 cents / minute is 378 especially unfair for many of those trying to earn a living on MTurk (LaPlante, personal 379 communication, March 18, 2015). A fairer rate that we have decided to adopt in our own research 380 is 15 cents / minute (as used by the third party service www.mTurkData.com). A keen eye will 381 spot that the wages reported above seem to increase year-by-year, which may be down to the 382 increasing proportions of North American MTurkers compared to other nationalities. Do be

383 advised, though, that those researchers using Mechanical Turk who are seen as offering too small 384 a financial incentive to participants for taking part in their study are often, and rightly so, the focus 385 of negative discussion on social media. Indeed, researchers should be aware that tools have been 386 developed that let the MTurkers evaluate the people providing their tasks (e.g., 387 https://turkopticon.ucsd.edu/), one of the parameters being 'fairness' in terms of pay (the others 388 being 'fast' again in terms of pay, 'fair' in terms of disputes, and 'communication' in terms of ease 389 of reaching the scientist; see Figure 4 for the first author's TurkOpticon Profile).

393 Of course, money is by no means the only motivating factor for those individuals who take part in 394 online research. Germine et al.'s (2012) successful replication of three classical studies online 395 (more on this study later) were based on data collected at http://www.TestMyBrain.org, where, in 396 exchange for partaking in the study, the participants were told how they performed in comparison 397 to the 'average' participant. To put into perspective how popular this kind of approach can be,

\footnotetext{
2 Tangentially, the lead author of this paper was approached after a recent talk given on the topic of this manuscript and was queried as to whether it was fair to pay online participants more than others do in their online studies, as this would presumably drive up the cost for all. Although a valid point, it is the lead author's view that such a payment ethos is not fair on the participants themselves.
} 
398 between 2009 and 2011, half a million individuals took part in a study on TestMyBrain. Indeed,

399 the rising popularity of such 'citizen science' projects would, we argue here, also offer an

400 incredible opportunity for other areas of science (see also https://www.zooniverse.org/ and

401 https:/implicit.harvard.edu/implicit/).

\section{Cross-cultural research}

403 The ability to write one experiment and run it with many participants from different cultures is 404 appealing (although language translation can be effortful). For example, identifying the extent to 405 which certain percepts are culturally-mediated has been useful for understanding a range of 406 perceptual phenomena, including colour vision (e.g., Berlin, 1991; Kay \& Regier, 2003), music 407 perception (e.g., Cross, 2001), and, from some of us, crossmodal correspondences / expectations 408 (e.g., Levitan et al., 2014; Wan et al, 2014a, 2014b, 2015).

409 Focusing on one example in more detail, Eriksson and Simpson (2010) were able to explicitly test 410 both US and Indian participants in their study on emotional reactions to playing the lottery. Their 411 results revealed that the female participants were less willing to enter the lottery than the male 412 participants, though the Indian participants were generally more willing to enter the lottery than 413 the North Americans. Their results also revealed that both male and female participants who were 414 willing to enter the lottery gave lower ratings on how bad they would feel about losing than their 415 counterparts who were not willing to enter the lottery. These findings allowed the researchers, at 416 least partially, to attribute the gender difference in risky behaviour to the different emotional 417 reactions to losing. Importantly, the researchers were able to observe the same results in two 418 samples from different countries, and also documented the cross-country difference in risky 419 behaviour.

\section{Complementing in-lab research}

421 As will become apparent in the sections that follow, it is unlikely that online research will subsume 422 everything that is done in the lab anytime soon. We believe, though, that online research can 423 certainly provide an especially helpful tool with which to complement lab-based research. For 424 example, if research is exploratory in nature, conducting it online first may help the researcher 425 scope out hypotheses, and prune out those alternatives that have little support. Subsequent lab 426 based research can then be run on the most promising subset of hypotheses. For example, our own 
427 research on crossmodal associations between basic tastes and the visual characteristics of stimuli, 428 started out 'online', where we explored basic associations between these elements. After having 429 found a link between round shapes and the word sweet, we then moved into the lab to test with 430 real sweet tastants in order to tease out the underlying mechanisms (see Velasco et al., 2015a; 431 Velasco, Woods, Liu, \& Spence, in press; see also Velasco et al., 2014, 2015b, for another example 432 of complementary online and offline research).

433 As online participants are less WEIRD than those in lab-based studies, following-up a lab-based 434 study with one conducted online may help strengthen the generalizability of one's initial findings 435 or, by means of a much larger sample, offer more conclusive proof of one's findings (e.g., 436 Knoeferle et al., 2015, Woods et al., 2012).

\section{Comparing online with in-lab}

438 Whilst questionnaire-based research readily lends itself to the online environment, a common 439 belief is that reaction-time (RT) studies, or those requiring fine temporal / spatial stimulus control 440 cannot readily be conducted online. Perhaps surprisingly then, to date, the majority of the 441 comparative non-questionnaire based studies that have been conducted, running essentially the 442 same study online and in the lab, have provided essentially consistent results. Indeed, this is 443 perhaps especially surprising, given the current replication crisis sweeping through the field of 444 psychology (Pashler \& Wagenmakers, 2012); although do consider that this preference to publish 445 findings based on low-power statistically significant effects as opposed to insignificant effects 446 potentially may be why the majority of online findings mirror those in lab. Of course, an alternative 447 scenario is that when faced with significant lab findings that don't replicate online, only the lab 448 findings eventually get published - the insignificant findings, as sadly is often the case, getting 449 relegated to the file drawer (Simonsohn, Nelson, \& Simmons, 2014; Spellman, 2012; refreshingly, 450 the journal Psychological Science now require authors to declare, amongst other things, that "all 451 independent variables or manipulations, whether successful or failed, have been reported in the 452 Method section(s)", Eich, 2014, p. 4).

453 Explicitly testing whether traditional lab based studies would work online, Germine et al. (2012) 454 successfully replicated five tasks that were thought to be particularly susceptible to issues such as 455 lapses in attention by participants and satisficing ('cheating', see Oppenheimer et al., 2009). 
456 Examples of such tasks were the Cambridge Face Memory Test, where faces are shown for three 457 seconds to be remembered later (Duchaine \& Nakayama, 2006) and the Forward Digit Span task, 458 which is concerned with the number of digits that can be recalled after being shown serially, one 459 after the other each for one second (Wechsler, 2008). Germine et al. (2012, p. 847) concluded that 460 '...web samples need not involve a trade-off between participant numbers and data quality.'

461 Similarly, Crump et al. (2013) replicated eight relatively well-established lab-based tasks online, 462 which the authors categorised as being either RT-based (such as the Erikson Flanker task, Erikson, 463 1995), focused on memory (e.g., concept learning, Shepard, Hovland, \& Kenkins, 1961), or 464 requiring the stimuli to be presented for only a short period of time. The only task that was not 465 completely replicated, a masked priming task (Eimer \& Schlaghecken, 1998), was in this latter 466 category, where visual leftward or rightward pointing arrows were presented for 16, 32, 48, 64, $46780,96 \mathrm{~ms}$ (or so it was assumed; more on this later) and the participant's task was to indicate the 468 direction in which the arrows pointed. In contrast to the original lab based study by Eimer and 469 Schlaghecken, the authors did not replicate the expected effects for stimuli of durations of 16-64 470 ms and concluded that short duration stimuli cannot be reliably shown when conducting internet471 based research.

472 In a similar vein, the Many Labs study (Klein et al., 2014) directly compared 13 effects across 36 473 samples and settings, including multiple online samples. The online samples came from 474 universities, from Mechanical Turk, and from a different online platform (Project Implicit) that 475 did not pay participants. Across all of these samples, very little difference in effect size was seen 476 between online and in-lab data.

477 The majority of the replication attempts by Germine et al. (2012), Crump et al. (2012), and Klein 478 et al. (2014) were successful. It would seem that only a subset of studies, specifically those 479 requiring short stimulus presentation, are not so well suited to online research. Indeed, as 480 mentioned by Crump et al., as technology improves, it is likely that even this category of task may 481 be achieved satisfactorily online. Who knows, there may come a time when lab and online research 482 are on a par in terms of data quality - indeed, given a disagreement between such studies, one 483 could argue that the effects from more ecologically valid scenario, the person being tested at home 484 in online research, should be treated preferentially as they would more likely also occur in the 
485 population at large. We will turn our attention to the issue of temporal precision later on, and 486 demonstrate that in some circumstances, such precision can actually be achieved today.

487 A popular argument is that, even if online research were more prone to error than traditional lab488 based research, simply by increasing the number of participants in one's study, the researcher can 489 offset such issues. In Simcox and Fiez's (2014, Experiment 2), 100 MTurkers took part in a 490 successful replication of a classic Erickson Flanker task (Nieuwenhuis, Stins, Posthuma, 491 Polderman, Boomsma, \& de Geus, 2006). In order to assess how many participants would need to 492 be tested in order to achieve an effect of a similar power to that observed in lab settings, the authors 493 systematically varied the number of participants contributing to identical analyses (10,000 random 494 re-samples per analysis). Reassuringly, a comparable number of online participants and in-lab 495 participants were required for the replicated effect to be observed. The authors also noted that by 496 increasing the sample size from 12 to 21, the chance of a Type 2 error (wrongly concluding that 497 no effect is present) dropped from $18 \%$ to $1 \%$ - in their study, this could be achieved by recruiting 498 additional participants for a total of $\$ 6.30$. Or expressed less sensationally, by collecting $75 \%$ more 499 participants for an additional cost of $75 \%$ of the original total participant fees.

500 So, although tasks requiring that visual stimuli be presented for especially short durations are 501 seemingly less suited for online research at present, in a few years, as proposed by Crump et al. 502 (2012), this position will likely change, thus making such research valuable to the research 503 community. Indeed, offsetting the reduced power of such experiments online with more 504 participants may help us bridge the gap between now and then.

\section{Potential concerns with online research}

507 It is important to acknowledge that there are a number of potential concerns with online research.

508 Below we try to answer some of the most common concerns that we have encountered in our own 509 research. Many of them, it has to be said, were raised by the inquisitive, sceptical, and downright 510 incredulous reviewers of our own papers. 


\section{1) Stimulus timing}

512 Getting a stimulus to appear on screen at the exact millisecond-specific time, and for the right

513 duration, is indeed very hard to achieve, even for lab-based software (see Garaizar et al., 2014;

514 Bauer, 2015); with online studies, the issue mostly boils down to the fact that the browser does not

515 know when the monitor refreshes (although see Gibhub, 2014) and so cannot synchronize stimulus

516 presentation with a given screen refresh. A consequence is that if a visual image is set to

517 appear/disappear between refreshes, it will only do so on the next refresh. Indeed, if a stimulus is

518 to appear and disappear within a period of time smaller than a refresh interval, it may not appear

519 at all, or could appear for (often much) longer than desired, and not at the right time. This is

520 probably why Crump et al. (2013) were unable to replicate the Flanker task for short duration

521 stimuli.

522 We tested this appearance issue in a simulation where we varied the duration of visual stimulus,

523 starting at a random time during the refresh cycle (10,000 virtual presentations per stimulus

524 duration). Figure 5 shows the likelihood of short duration stimuli being shown at all, or being

525 shown for the wrong duration, or starting / stopping at the wrong time

526 (https://github.com/andytwoods/refreshSimulation; available to run / tweak online here

527 http://jsfiddle.net/andytwoods/0f56hmaf/). As most people use LCD monitors which typically

528 either refresh 60 ( $78.1 \%$ of monitors) or 59 times a second ( $21.9 \%$ of monitors), we know that the

529 majority of screens refresh every $16.67 \mathrm{~ms}$ or $16.95 \mathrm{~ms}$ (Witzel et al., 2013). As shown in Figure

5305 , thus, by having none of your stimuli shown for less than $16.95 \mathrm{~ms}$, the stimulus should appear

531 on screen for about the correct duration and ( $>90 \%$ of the time). Specifying your stimulus durations

532 as multiples of $16.95 \mathrm{~ms}$ will also lead to more accurately presented longer-duration stimuli.

533 Indeed, one may wonder why the majority of research software packages do not allow

534 experimenters to specify their stimuli in terms of refresh intervals (as only done by DMDX, to the

535 best of our knowledge).

536

537

538

539

540

541

\section{-Figure 5 about here-}

Auditory stimuli and the variability in the hardware they are generated by pose similar problems. For example, Plant and Turner (2009) found that computer speaker systems introduced a delay 
542 before audio presentation, that ranged anywhere from $3.31 \mathrm{~ms}$ all the way up to $37 \mathrm{~ms}$ (respective

543 standard deviations of 0.02 and $1.31 \mathrm{~ms}$ ), with the duration of the sound varying by 1-2 ms across

544 systems. Previous work has also found that auditory information is sometimes treated differently

545 depending on whether participants wear headphones or hear sounds through speakers (Di Luca,

546 Machulla, \& Ernst, 2009; though see also Spence, 2007). One option is that the researcher may

547 wish to include questions pertaining to the participants' audio hardware. Needless to say, tasks that

548 require the fine temporal control of auditory and visual stimuli, such as needed in the visual flash

549 illusion (Shams, Kamitani, \& Shamojo, 2002) and McGurk effect (McGurk \& MacDonald, 1976),

550 perhaps would best be undertaken in the lab (if relatively few such stimuli are needed though, and

551 latency issues with speaker presentation of sound aside, combining video and audio into videos

552 may be an effective first step in ensuring accurate timing; the interested reader is referred to a blog 553 article describing how timecodes can help preserve timing,

554 http://www.bbc.co.uk/blogs/legacy/bbcinternet/2011/02/frame_accurate_video_in_html5.html).

555 Although do consider that if such an illusion / effect were reliable enough, a staircase procedure

556 could be used to identify the delay required for auditory and visual elements to be perceptually

557 synchronous, which could then be used to calibrate subsequent auditory-visual testing on that

558 computer.

\section{2) Reaction times}

560 A consequence of not knowing when the screen refreshes, and thus not knowing when a stimulus

561 will appear on the participant's screen, is that, it is hard to know from when exactly RTs should

562 be measured (visit https://cogsci.stackexchange.com/questions/9584/how-valid-are-reaction-

563 times-collected-from-online-studies/9967\#9967 for an ongoing discussion about the quality of

564 reaction time data collected online; do note that external hardware issues aside, sub-millisecond is

565 possible through a web-browser http://www.w3.org/TR/hr-time/). Another issue is that RTs

566 unfortunately vary quite considerably depending on the brand of keyboard used in a study, which

567 is most certainly a big issue with online research. Plant and Turner (2009) found, for example,

568 that the mean delay between button press and reported time was between $18.30 \mathrm{~ms}$ to $33.73 \mathrm{~ms}$ for

5694 different PC keyboards (standard deviations ranged between $.83 \mathrm{~ms}$ and $3.68 \mathrm{~ms}$ ). With

570 Macintosh computers, Neath et al (2011) found that keyboards added a delay between $19.69 \mathrm{~ms}$

571 and $39.56 \mathrm{~ms}$ (standard deviations were between $2.67 \mathrm{~ms}$ and $2.72 \mathrm{~ms}$ ). In a lab setting, this is not 
572 such an issue where typically participants are tested using the same experimental apparatus and 573 thus same keyboard (example $5 \mathrm{~ms}$ response delays with a random variation of $-2.7 \mathrm{~ms}$ to $+2.7 \mathrm{~ms}$ 574 are 22.11, 18.07, 17.59, 20.9, $22.3 \mathrm{~ms}$; mean=20.19, stdev=2.23). However, when lots of different

575 keyboards are used, a whole variety of different latencies act to introduce troublesome variation 576 (example 5 random response delays of $20 \mathrm{~ms}$ to $40 \mathrm{~ms}$, with the same random variation added are $57719.45,37.8,37.57,22.7,31.23 \mathrm{~ms}$; mean=29.75, stdev=8.43).

578 All is not lost however. Systematically exploring how well RTs could actually be measured online, 579 Reimers and Stewart (2014) recently tested RTs on 5 different computers, 3 web-browsers, and 2 580 types of web-technology (Adobe Flash, HTML 5) using a Black Box Toolkit 581 (http://www.blackboxtoolkit.com/; a piece of hardware that can be used to accurately measure 582 response times and generate button presses). The authors used the device to detect screen flashes 583 generated by the testing software by means of a photodiode, and to generate button presses at 584 precise times by completing the circuit of a button of a hacked keyboard. Although there was some 585 variability across machines, and although RTs were generally overestimated by $30 \mathrm{~ms}$ (comparable 586 to the delays reported above, although standard deviations were typically $10 \mathrm{~ms}$ ), the authors 587 concluded that the noise introduced by such technical issues would only minimally reduce the 588 power of online studies (the authors also suggested that the within-participant design is particularly 589 suited to online research given this variability). Once again bolstering the support for conducting 590 valid RT research online, Schubert, Murteira, Collins, and Lopes (2013) found comparable RT 591 measurement variability when comparing their own online Flash-based research software 592 ScriptingRT (mean $92.80 \mathrm{~ms}$, standard deviation 4.21) with lab-based software using the 593 photodiode technique mentioned above (millisecond mean reaction times for DMDX, E-prime, 594 Inquisit and Superlab, were respectively $68.24,70.96,70.05,98.18$; standard deviations 3.18, 3.30, 5953.20 and 4.17; the authors must be commended for their 'citizen science' low-cost Arduino-based 596 timing solution, which Thomas Schubert fleshes out on his blog 597 https://reactiontimes.wordpress.com/). These findings were broadly mirrored by de Leeuw and 598 Motz (in press) who compared accuracy for recording RTs in a visual search task that run either 599 via Matlab's Psychophysics ToolBox or in a webbrowser via JavaScript. Whilst RTs for the latter 600 were about $25 \mathrm{~ms}$ longer than the former, reassuringly there were no real differences in data 601 variability over platforms. Simcox and Fiez (2014) found that browser timing accuracy was only 602 compromised when unusually large amounts of system resources were in use. The authors 
603 measured timing by externally measuring screen flashes with a photodiode that were placed 1000 $604 \mathrm{~ms}$ apart in time, and concluded that browser based timing is in most scenarios as accurate as lab605 based software. In summary, then, it would seem then that the variability introduced by participants 606 using different computers / monitors / web-browsers, is negligible in comparison to the variability 607 introduced by the participants themselves (Brand \& Bradley, 2012; Reimers \& Stewart, 2014), 608 although, one has to wonder whether using the participant's smartphone-camera to detect screen 609 refresh / stimulus presentation parameters (from say a few pixels devoted to this purpose in the top 610 of the participants' screen) and appropriately feeding this knowledge back to the testing software 611 may help with accuracy. Some modern day cameras certainly are able to capture video at high 612 enough frame rates (e.g., $120 \mathrm{~Hz}$, Haston, 2014).

613 One way to get around the browser-related limitations of not knowing when the screen refreshes 614 is to ask participants to download experimental software to run outside of the browser 615 (unfortunately MTurk does not permit the downloading of external software; Prolific Academic 616 does allow this if sufficient explanation is provided for the participants). One problem here though 617 is that the experimenter cannot really ask their participants to undertake the fine calibrations 618 normally required to set up experimental lab-based software (e.g., timeDX, 619 http://psyl.psych.arizona.edu/ jforster/dmdx/help/timedxhtimedxhelp.htm), so more superficial 620 means of calibration must be automatically undertaken. Seeing if their own compromise solution 621 were sufficient for the downloadable webDMDX, Witzel et al (2013) tested whether the results of 622 classical time critical studies differed across lab based DMDX (Forster \& Forster, 2003) and 623 webDMDX and found good consistency across software platforms. Curiously, however, the results 624 of a stimulus that had been set up to appear for $50 \mathrm{~ms}$ in the lab-based software matched those for 625 a $67 \mathrm{~ms}$ duration stimulus in the web based software. The authors found that the lab-based stimulus 626 was just over 3 refreshes in length $(16.67 \mathrm{~ms} * 3=50.01 \mathrm{~ms})$ and so was actually shown for an 627 additional interval, for $66.68 \mathrm{~ms}$, as was $67 \mathrm{~ms}$ stimulus (n.b., DMDX rounds to the nearest refresh 628 interval), which was easily corrected. Thus, if your participants trust your software, and your 629 participant panel permits it, it may be advisable to use software like webDMDX for those 630 experiments requiring fine temporal control of stimuli. 


\section{3) Variability in hardware}

632 Perhaps the most obvious issue with online research, as alluded to above, is the sheer variety of

633 hardware and software used by participants. Although it can be argued that online research is more

634 ecologically valid because of this varied hardware compared to lab-based studies that all run on

635 the same device, hardware variability, nevertheless, poses some unique challenges for the 636 experimenter; especially when considering that the web browser can only determine a few device 637 parameters such as screen resolution and operating system (but see Lin et al., 2012). For example, 638 the resolutions of monitors differ massively over participants; we found in 2013 an average 639 resolution of $1422 \times 867$ pixels over 100 participants' monitors, with large respective standard 640 deviations of 243 and 136 pixels (Woods et al 2013). As there is no way to assess the physical size 641 of monitors via a web browser, standardising the size of one's stimuli over participants is extremely 642 difficult. As a work around, Bechlivanidis \& Lagnado (submitted) had their participants hold up 643 a CD, a credit card, or a 1 US dollar bill to their screen, and then adjust a shape on the screen to 644 match the size of the object (see also Yung, Cardoso-Leite, Dale, Bavelier \& Green, 2015). The 645 authors also asked their participants whether they were an arm's distance away from their monitor 646 to get an idea of their distance from the monitor (see also Krantz, who suggests a real world 'rule 647 of thumb' - by holding your thumb an arm's distance from the monitor, perpendicular elements 648 directly beneath the thumb are approximately 1 or 2 visual degrees, 2001). Another approach is to 649 find your participant's blind spot—-by asking the participant to focus on a shape whilst another 650 shape horizontally moves relative to it, and indicate when the moving shape disappears from 651 view - and then resize experimental images appropriately. Sadly though, we cannot anchor our 652 online participants' heads in place to prevent fidgeting, although, as suggested by a helpful 653 audience member in a recent talk by the first author, monitoring the participant via a webcam and 654 resizing stimuli appropriately may be one future strategy to help cope with this.

655 Another issue is that the many dials and buttons that adorn the modern-day computer often make 656 it impossible to quantify properties such as volume, brightness, and colour. There are, though, 657 ways to counter this issue. For example, the participant could be asked to adjust the volume until 658 an audio stimulus is just audible, or indicate when elements in a visual image have the highest 659 contrast (To, Woods, Goldstein, \& Peli, 2013). Yung et al. (2015) did the latter by presenting a 660 band of grey bars on screen and having their participants adjust the brightness of the bar (in their 661 software) until all of the bars were visible. We have also started to include an audio password (or 
662 AudibleCaptcha) in our experiments that can only be answered when the volume is set 663 appropriately (Knöferle, Woods, Käppler, \& Spence, 2015). The daring may even consider using 664 staircases to establish a variety of thresholds for audio stimuli. Although it is impossible to really 665 control for background noise levels, by using webcam microphones, it may be possible to quantify 666 background noise levels and re-run noisy trials or add noise levels as a covariate in subsequent 667 data analyses.

668 Perhaps one of the greatest challenges is colour. Although one approach to combating this issue is 669 to use colour words instead of the colours themselves (e.g., Piqueras-Fiszman, Velasco, \& Spence, 670 2012; Velasco et al., 2014); though, of course, this solution is only going to be suitable for a small 671 number of studies (those that only use colour categories). An initially promising solution would 672 be to run studies on identical devices such as the same generation iPad device.

673 Unfortunately, however, even purportedly identical screens viewed in identical environmental 674 conditions vary in terms of colour and brightness (Cambridge Research Systems, personal 675 communication, February 17-18, 2015). Others have suggested using psychophysics to identify 676 issues with the current monitor and then dynamically adjusting the presented images appropriately. 677 Our hats come off to To, Woods, Goldstein, and Peli (2013); they presented a variety of coloured 678 and hashed line patches in different shades and had their participants adjust their properties so that, 679 for example, two such patches would match in terms of their brightness. The authors found that 680 participants performed to a similar ability to a photometer (.5\% sensitivity difference). A potential 681 future solution could be to ask participants to use the camera on their mobile devices to video both 682 their computer screen being used for a study, and a common, colourful, household object, (e.g., a 683 bottle of CocaCola ${ }^{\mathrm{TM}}$; cf. the size solution of Bechlivanidis \& Lagnado, submitted). Software on 684 the mobile device could then potentially liaise with the research software to calibrate screen colour 685 to the reference object. Thus, although presenting the same colour to participants irrespective of 686 device is probably not achievable with current technologies, we believe that there are some nice 687 'work-arounds' that may help somewhat offset any variability in one's data due to inconsistent 688 colour (as can also be done by collecting data from many more participants).

689 Briefly summarising, the variability in hardware used by participants in online studies pose unique 690 problems that with the current level of technology are hard to directly address. Several 691 workarounds exist for each issue however, and in the end of the day, collecting more data (as 
692 always) is a healthy way to offset some of these issues. Of course, hardware-related data variability

693 can be factored out in subsequent data analyses if a within-participants design can be used over a

694 design where groups of participants' data (and differing variation due to hardware variability) are 695 contrasted against each other.

697 4) Unique participants?

698 How can you be sure that the same participant is not taking part in the experiment multiple times?

699 Participants recruited through Mechanical Turk or Prolific Academic must have an online profile

700 that theoretically prevents them from taking part in the same study more than once. Although 701 potentially an individual can have multiple accounts, it is harder to do these days with increasingly 702 tight security-conscious sign-up criteria. Indeed, if the participant wishes to get paid, they must 703 provide unique bank account and Social Security Number details (for MTurk), each of which 704 requires a plethora of further identification checks (as does PayPal, which Prolific Academic 705 currently uses for participant payment).

706 The research software itself can also provide some checks for uniqueness, for example, by storing 707 a unique ID in each participant's web browser cache or Flash cache, thus making it easier to identify 708 repeat participants. Although it is sometimes possible to identify potential repeaters by means of 709 their (identical) IP address, Berinsky et al. (2012) noted that the 7 out of 551 participants in their 710 Mechanical Turk study who had identical IP addresses, could well have performed the study on 711 the same computer, or same shared internet connection; indeed, this day and age, the participants 712 could even have done the study through the same Virtual Private Network and be in quite different 713 geographic locations from those determined via IP address (or indeed through self-report).

714 A related concern arises when an experimenter conducts multiple different online experiments 715 using the same platform. Preventing previous participants from participating in future experiments 716 is difficult using Mechanical Turk (but see http://mechanicalturk.typepad.com/blog/2014/07/new717 qualification-comparators-add-greater-flexibility-to-qualifications-.html), so typically the 718 experimenter ends up having to manually, tediously, exclude repeats after participation. Bear in 719 mind here that relying on participants to not undertake a task if they have done a similar one in the 720 past is unfair given the sheer number of past studies each likely will have undertaken. Perhaps a 721 much more impactful issue is when participants become overly familiar with popular experimental 
722 methods / questionnaires that are used by different researchers. Highlighting this issue, Chandler,

723 Mueller, and Paolacci (2014) found that out of 16,409 participants in over 132 studies, there were

724 only 7,498 unique workers with the most active $1 \%$ completed $11 \%$ of hits (see also Berinsky,

725 Huber, \& Lenz, 2012; Stewart, Ungemach, Harris, Bartels, \& Newell, submitted).

726 Although these issues most certainly are a concern for researchers focusing on the study of 727 perception, it is likely that repeat participants would be far more problematic for more cognitive-

728 focused areas of psychology. It may simply be the case for the psychologist interested in perception

729 to ask participants how often they have undertaken similar tests in the past and use this data a 730 covariate in their subsequent statistical analysis.

\section{5) Random responding}

733 A common concern with online research is that those taking part in a paid study do not do so with 734 the same care and diligence as those in a lab-based study. In fact, however, the research that has

735 been conducted in this area to date shows that lab-based studies are not necessarily the gold 736 standard that we often presume. In one such study, conducted by Oppenheimer, Meyvis, and 737 Davidenko (2009), immediately after completing two classic judgement and decision-making 738 studies, participants were presented with a catch-trial in which they were explicitly told to click a 739 small circle at the bottom of the screen, as opposed to one of 9 response buttons making up a line 740 scale that was shown in the centre of the screen. Not only did a disquieting $46 \%$ of the participants

741 fail the task, but only by excluding these individuals were both the classic tasks successfully 742 replicated (interestingly, in a second study, individuals had to redo the task until they got it correct 743 - performance on the subsequent classic task no longer varies as a function of being 'caught out' 744 in the catch task). Thus one cannot necessarily assume that the participants in lab-based research 745 are attending as carefully as one might hope. As an example from our own experiences, one author 746 received a text message from such a participant who was 'mid study', saying they would be late 747 for his later experiment! Reassuringly though, perhaps again highlighting that perceptual 748 psychology is more robust to such issues than other areas of our discipline, some of us used the 749 Oppenheimer et al. (2009) attention check for an online face emotion task and found that only $1 \%$ 750 of MTurkers failed the task (Dalili, 2015; see Hauser \& Schwarz, 2015 for an in depth discussion).

751 We return to this issue below. 
752 Perhaps one key issue scientists have with online research is the absence of the experimenter who 753 can be quizzed to clear up uncertainties, or to make sure that the participant follows the 754 instructions. Painting a bleak picture, Chandler, Mueller, and Paolacci (2014) asked 300 MTurkers 755 what they were doing whilst completing a study, and found that $18 \%$ of responders were watching $756 \mathrm{TV}, 14 \%$ listening to music and $6 \%$ were communicating with others online (the interested reader 757 is directed to a video where an MTurker discusses this issue in reference to looking after her baby 758 whilst participating in research, Marder, 2015). Several strategies, besides the catch trial 759 mentioned earlier (Oppenheimer et al., 2009), have been developed to deal with the consequences 760 of such distraction and potential disinterest (Downs, Holbrook, Sheng, \& Cranor, 2010, Crump, 761 McDonnel, \& Gureckis, 2013; Germine et al., 2012), perhaps the simplest being to quiz the 762 participants as to the nature of the task before proceeding to the study. Crump et al. found that this 763 approach led to a close replication of a classic rule-based classification learning study (Nosofsky, 764 Gluck, Palmeri, McKinley, \& Glauthier, 1994), compared to an earlier study where there was no 765 such intervention (as would also seem to be demonstrated in Experiment 2 of Oppenheimer, 766 Meyvis, and Davidenko, 2009, mentioned in the preceding paragraph).

767 Indicating that this is not such an issue, when Hauser and Schwarz (2015) directly set about 768 comparing the performance of lab-based and internet recruited participants on the Oppenheimer, 769 Meyvis, and Davidenko (2009) catch trial, and found the latter group much less likely to fail at the 770 task. Hauser and Schwarz first found that lab-based participants failed an astounding $61 \%$ of the 771 time - even more than the original study - whilst online participants recruited on MTurk only 772 failed $5 \%$ of the time. This broad pattern of results was replicated for a novel version of the catch 773 trial in Experiment 2. To test whether MTurkers were just very vigilant for such catch trials (as 774 they may have had similar ones in the past; see the 'overfamiliarity' discussion above) or whether, 775 indeed, MTurkers paid more attention, in a third study, both groups were tested on a soda-pricing 776 task (once again adapted from Oppenheimer et al., 2009) that has been shown to be sensitive to

777 levels of attention. Supporting the latter account, the online participants scored much better in a 778 test that was sensitive to attention levels than their lab-based counterparts.

779 In summary, whilst the lack of experimenter supervision for participants recruited online most 780 certainly is worrying, it is important to bear in mind that lab-based research does not necessarily 781 ensure attentive participants either. The very fact that a lot of past research has been replicated 
782 would indicate that the different issues with online and in lab research may be similarly impactful 783 on results in our field.

\section{6) Ethics}

786 While it is relatively clear where the responsibility lies for ethics in a study conducted within a 787 given department, online research is often an unknown area for both the researcher and the local 788 ethics committee. The British Psychology Society have weighed in on this topic (British 789 Psychological Society, 2006, 2013; see also the American Psychological Association's overview on this, Kraut et al., 2004; Ross 2014), highlighting the key issue that it is the physical absence of the experimenter during the study, preventing, for example, the experimenter from stopping the study early if the participant starts showing any signs of distress. Presumably though, the online participant would anyway feel less obligation to actually finish a study they that were uncomfortable with, compared to if it were a lab-based study.

There are several other issues as well (for a timely special issue focused on 'ethical issues in online research' see, James \& Bushner, 2015). Besides issues of fair pay (highlighted earlier), online anonymity is also a key issue. For example, with a bit of deduction, it is often possible to extrapolate the identity of an individual from their pattern of responses (El Emam \& Arbuckle, 2013; King, 2011; see also some such high-profile examples from the Netflix challenge, Narayanan \& Shmatikov, 2008, and social networks, Narayanan \& Shmatikov, 2009). Highlighting this, MTurker Worker IDs are made available to research software when people take part in an MTurk study. We asked 100 MTurkers to enter their Worker ID into Google and tell us 'Did your Google search of your Worker ID find links to 'raw data' (answers you gave) from previous studies you have taken part in?" and "Did your Google search results contain information that revealed your name or IP address?" A staggering 47 MTurkers reported finding such past data in their search results, whilst 5 MTurkers reported finding their name / IP-address. Further exploration is warranted to check just what information past researchers are making publicly available online alongside potentially identity revealing MTurker Worker IDs, as this clearly goes

809 against ethical guidelines. Several MTurkers also emailed to say that their past Amazon store

810 reviews of books appeared in their search results - with a bit of investigation it transpired that 811 Amazon Ids and MTurker Worker IDs are one and the same (see Lease et al. 2013, who discuss 
812 this and other issues in detail)!. In light of the above, we would urge researchers to carefully select

813 the information that is stored alongside collected data, and to remove Worker IDs before sharing

814 data online. If Worker ID data must be stored online (e.g., to be shared by the members of a specific

815 lab), that data should be adequately encrypted, and not left as 'plain text' as was seen often in the

816 just mentioned survey.

817 The recent drive to opensource datasets coupled with the ethical requirement to allow participants

818 to withdraw their data after data collection (up to a certain point in time, anyway, such as at the

819 conclusion of the analysis) unfortunately muddies the waters regarding anonymity. One strategy

820 for this we have adopted is to ask participants to provide a password that can be used if they wish

821 their data removed by a later date; although given the large number of passwords one must

822 remember these days, it is not clear if this will prove effective. The School of Experimental

823 Psychology in Bristol has provided a carefully thought-out example of a Participant Information

824 Sheet and Consent Sheet package which takes this and other issues into account (M. R. Munafò,

825 personal communication, April 30, 2015). Given the ever changing landscape of online research

826 we feel (along with an anonymous reviewer) that the BPS and APA perhaps need to re-assess their

827 policies in light of the above anonymity revelation, and on a regular basis, following in the

828 footsteps of Bristol's well-applauded example ethics documentation.

829 Software to conduct research online

830 In 2004, the lead author devoted several months creating a one-off website to run a JavaScript-

831 powered study on crossmodal face perception using videos (Stapleton, Woods, Casey, \& Newell,

832 submitted; see Thompson, 1996, for an early pre-JavaScript experiment run entirely in HTML).

833 Things have progressed a great deal since then! There are now a variety of software platforms

834 aimed at collecting questionnaire-based data online, with a smaller number of packages now aimed

835 specifically at conducting online behavioural research. Some of the latter, alongside their strengths

836 and weakness as reported by their main developers, have been listed in Table 3.

837 One way in which the packages differ is in terms of whether they are opensource or commercial

838 in nature. Whilst licensed software is often thought to be easier to use and have a better support

839 network than opensource software, a downside is that if a bug is found, you are at the mercy of a

840 limited number of developers to fix the problem, instead of being able to immediately explore the 
841 code yourself or to ask for help from the lively opensource community. Conventional wisdom

842 would also suggest that commercial software would be easy and more versatile than opensource

843 'freely contributed to' software but the reality is that this is often not the case (e.g., The Gimp,

844 http://www.gimp.org/, is an opensource feature rich alternative to Adobe Photoshop). Moreover,

845 commercial software is typically configured with the needs of large-scale corporate users in mind,

846 whereas the opensource community may be more receptive to suggestions that benefit academic

847 users.

848 If you have no programming experience, deciding on a testing package that does not require the 849 coding may be a quicker option for getting a study on the web, if your task only requires typical 850 experimental features (such as buttons, scales, the ability to show pictures, etc). Some packages 851 such as Qualtrics and Tatool, for example, let you create studies by dragging and dropping 852 components on screen. An intermediate option offering more flexibility is to use software that 853 relies of scripts to run an experiment (e.g., ScriptingRT, WebDMDX, Xperiment).

854 Whether or not the research software is Adobe Flash based or not is another consideration. 855 Although Flash has purportedly been 'dying' for a number of years now, it is, in fact, still present 856 on most modern computers; for example, it is installed automatically within the Chrome web 857 browser which has 61.9\% market share (Browser Statistics, 2015), and can be automatically 858 installed in other popular browsers such as Firefox (23.4\% market share). Flash is also making a 859 comeback by re-inventing itself as a cross-platform tool capable of making apps for both Android 860 and IOS; indeed, it won the 2015 Consumer Electronics Show best mobile application 861 development platform. As we found out recently, though, given the lead author's package called 862 Xperiment, reliance on the proprietary closed-source Adobe Flash environment meant that when 863 bugs in closed source code did arise, we were entirely dependent upon Adobe engineers to fix the 864 issues. At the start of 2014, Adobe updated their software and thus 'broke' an experiment we were 865 running, leading to a loss of $31.3 \%$ of participant data (see the bug here 866 https://productforums.google.com/forum/m/\#!topic/chrome/ifL98iTMhPs). This may well have 867 been due to 'teething issues' due to Google Chrome releasing its own version of Flash around that 868 time called 'pepperFlash'. In light of this, though, the lead author is porting over the Xperiment 869 package to the opensource cross-platform Haxe toolkit, which allows software to natively run in 870 the browser (without Flash), as well on several platforms such as IOS and Android. 


\section{On the future of online perception research}

875 We believe that smart devices will come into their own in the coming years (e.g., Brown et al., 876 2014; Dufau et al., 2011; Millar, 2013). Making them seem particularly well suited for online 877 perceptual psychology are their plethora of sensors (light levels, global position system, proximity) 878 and actuators (vibration, flashing light), as well as their range of peripherals such as smart watches 879 (letting you measure for example, heart rate, cadence, and even sleep quality), other wearables 880 such as motion tracking (e.g., http://www.xensr.com/) and even intelligent cushions that measure 881 seated posture quality (http://darma.co/). Of course, these new technologies may well be affected 882 by the same issues that were highlighted before. For example, in our own tentative steps down the 883 road of smart phone research, we have found large differences in terms of the levels of vibration 884 that different smartphones can produce, which is, presumably attributable to the devices using a 885 variety of vibration motors.

886 Not only are smart devices rich in sensors and actuators, they can add a new dimension to research

887 by being able to contact participants at any point during the day using Push notifications, or to link 888 with software services to provide even richer sources of information for your investigation. If a 889 study were concerned say, with vibration detection in noisy environments, the device could be 890 made to vibrate only when the background noise level was at a desired level. Alternatively, GPS 891 could be used if your paradigm required participants only be tested in certain geographical 892 locations. We predict such 'mashups' of technologies (e.g., Paredes-Valverde, Alor-Hernández,

893 Rodríguez-González, Valencia-García, \& Jiménez-Domingo, 2015) will really be a game changer 894 for perceptual psychology (for some predictions on future ways we will interact with our devices, 895 see Nijholt, 2014).

896 Unfortunately, the current state of affairs mirrors that for online research in 2005 where one-off 897 experiment apps must be made, typically for either IOS or Android devices. An early example of 898 such an app, reported in 2010, by Killingsworth and Gilbert, had participants' iPhones, ask their 899 users a series of questions to do with their current levels of mind wandering and happiness 900 randomly throughout the day. Curiously, the authors found that mind-wandering was negatively 
901 associated with happiness (although more recent findings suggests that this affect depends upon 902 the mind wandering being negative itself in terms of emotion, Poerio, Totterdell, \& Miles, 2013).

903 Conducting research on gaming devices such as the Xbox One and Playstation 4 is surprisingly 904 not that far away. Transpilers, or source-to-source compilers (Source-to-source compiler, n.d.) 905 allow developers to write code once and port that code to different platforms and programming 906 languages. A transpiler that can currently port code to such gaming devices is the commercially 907 available Unity 3D package (http://unity3d.com/; see also Adobe Air and the opensource Haxe 908 platform; as of yet though, neither package can port to gaming devices; 909 https://www.adobe.com/uk/products/air.html, http://haxe.org/).

910 'Big data' is most certainly part of the future for psychological research, where hundreds of 911 thousands of participants contribute data as opposite to tens or hundreds as seen in typical lab912 based studies. To attract these numbers, researchers, for example, gamify their paradigm to make 913 it fun for people to take part, offer feedback about how people have done after task completion 914 (e.g., testMyBrain that we mentioned earlier providing score feedback). An alternative strategy is 915 to piggyback existing sources of data, as Stafford and Dewar (2014) nicely demonstrate with their $916 \mathrm{n}=854,064$ study exploring skill learning whilst people played an online game called Axon, that 917 was developed for the Wellcome Trust (http://axon.wellcomeapps.com/).

918 In China, around 10:34 pm on Thursday 19, 2015 (The Chinese New Year), apparently 810 million 919 smartphones were shaken at their TVs every minute. Over the course of a 4-hour long show 920 (China Central Television Spring Festival gala), the shake count totalled an incredible 11 billion! 921 What had happened was that weChat (a Chinese instant messaging service) in collaboration with 922 a plethora of retail companies had offered the public the possibility of winning 'red envelopes' 923 containing small amounts of money (for example, 2 Chinese Yuan, or about 0.32 USD), by just 924 shaking their phones. One can only wonder what could be achieved if an intrepid researcher 925 managed somehow to piggyback this, a la Stafford and Dewar (2014). Careful care would needed 926 to ensure such a study was ethnically sound, however (c.f. the recent Facebook emotion 927 manipulation study, as discussed by Ross, 2014). 


\section{Conclusions}

929 Over the last 5 years or so, we have found the internet to be a very effective means of conducting 930 online research to address a number of perceptual research questions. It offers a number of

931 potential benefits over in-lab testing and is particularly useful for quickly collecting a large amount

932 of data across a relatively wide range of participants. On the flip-side, there are a number of 933 potential limitations that also need to be borne in mind. In terms of ethics, it seems that online 934 participants are not as anonymous as they should be, which needs addressing. It is also tricky to 935 account for differences in hardware over machines and there still remain some issues related to the 936 fine control of timing. Over the coming years though, it is likely that such issues will become less 937 of a problem as technology develops, new solutions arise, and clearer ethical guidelines become 938 available to researchers. In the meantime, a simple approach to deal with some of these issues 939 though is, as always, to collect more data, which fortunately is easy, economical and fast in online 940 research. As with the introduction of the personal computer to the psychology lab, we feel that

941 online research will revolutionize the way in which we investigate perceptual processes.

942 ACKNOWLEDGEMENTS: We are grateful for feedback on an earlier draft of this manuscript by 943 Rochelle LaPlante, Kristy Milland, Marcus Munafò, and Six Silberman.

947Admin. (2013, January 17). The reasons why Amazon Mechanical Turk no longer accepts 948 international Turkers. $\quad$ Retrieved March 7, 2015, from

949 http://turkrequesters.blogspot.co.uk/2013/01/the-reasons-why-amazon-mechanical-turk.html 950Aiello, L. M., Barrat, A., Schifanella, R., Cattuto, C., Markines, B., \& Menczer, F. (2012). Friendship 951 prediction and homophily in social media. ACM Transactions on the Web (TWEB), 6(2), 9.

953auer, B. (2015). A timely reminder about stimulus display times and other presentation parameters 953 on CRTs and newer technologies. Canadian Journal of Experimental Psychology. 2015 Mar 16. 954 [Epub ahead of print] PMID: 25774997 
95Bechlivanidis, C. \& Lagnado, D.A. (submitted). Time reordered: Causal perception guides the 956 interpretation of temporal order. Cognition.

95Behrend, T. S., Sharek, D. J., Meade, A. W., \& Wiebe, E. N. (2011). The viability of crowdsourcing 958 for survey research. Behavior Research Methods, 43, 800-813.

95\$erinsky, A. J., Huber, G. A., \& Lenz, G. S. (2012). Evaluating online labor markets for experimental 960 research: Amazon.com's Mechanical Turk. Political Analysis, 20, 351-368.

961Berlin, B. (1991). Basic color terms: Their universality and evolution. Oxford, UK: University of 962 California Press.

963Brand, A., \& Bradley, M. T. (2012). Assessing the effects of technical variance on the statistical 964 outcomes of web experiments measuring response times. Social Science Computer Review, 30, $965 \quad 350-357$.

966British Psychological Society (2006). Report of the Working Party on Conducting Research on the 967 Internet: Guidelines for ethical practice in psychological research online. REP62/06.2007.

968British Psychological Society (2013). Ethics Guidelines for Internet-mediated Research. 969 INF206/1.2013. Available from:www.bps.org.uk/publications/policy-andguidelines/research970 guidelines-policydocuments/research-guidelines-poli

97 Brown, H. R., Zeidman, P., Smittenaar, P., Adams, R. A., McNab, F., Rutledge, R. B., \& Dolan, R. J. 972 (2014). Crowdsourcing for cognitive science - The utility of smartphones. PLoS ONE, 9, e100662.

973rowser Statistics. (2015, January 1). Retrieved February 7, 2015, from 974 http://www.w3schools.com/browsers/browsers stats.asp

97ßuhrmester, M., Kwang, T., \& Gosling, S. D. (2011). Amazon's Mechanical Turk: A new source of 976 inexpensive, yet high-quality, data? Perspectives on Psychological Science, 6, 3-5.

97Thandler, J., Mueller, P., \& Paolacci, G. (2014). Nonnaïveté among Amazon Mechanical Turk 978 workers: Consequences and solutions for behavioural researchers. Behavioural Research Methods, 979 46, 112-130.

980handler, J., Paolacci, G., \& Mueller, P. (2013). Risks and rewards of crowdsourcing marketplaces. 981 In P. Michelucci (Ed.), Handbook of human computation (pp. 377-392). New York, NY: Springer. 
982Cross, I. (2001). Music, cognition, culture, and evolution. Annals of the New York Academy of 983 Sciences, 930, $28-42$.

984Crump, J. C., McDonnel, J. V., \& Gureckis, T. M. (2013). Evaluating Amazon's Mechanical Turk as 985 a tool for experimental behavioural research. PLoS ONE, 8, e57410.

986alili, M. (2015, March 20). TARG Blog » Research doesn't just happen in the lab anymore: 987 Mechanical Turk, Prolific Academic, and online testing. Retrieved March 20, 2015, from 988 http://targ.blogs.ilrt.org/2015/03/20/research-doesnt-just-happen-in-the-lab-anymore-

989 mechanical-turk-prolific-academic-and-online-testing/

990e Leeuw, J. R. \& Motz, B. A. (in press). Psychophysics in a web browser? Comparing response 991 times collect with JavaScript and Psychophyiscs Toolbox in a visual search task. Behavior 992 Research Methods.

993Di Luca, M., Machulla, T. K., \& Ernst, M. O. (2009). Recalibration of multisensory simultaneity: 994 Cross-modal transfer coincides with a change in perceptual latency. Journal of Vision, 9, 7.

995Downs, J. S., Holbrook, M. B., Sheng, S., \& Cranor, L. F. (2010). Are your participants gaming the 996 system? Screening Mechanical Turk workers. In Proceedings of the SIGCHI Conference on 997 Human Factors in Computing Systems (pp. 2399-2402). New York, NY. ACM.

998oyen, S., Klein, O., Pichon, C. L., \& Cleeremans, A. (2012). Behavioral priming: It's all in the mind, 999 but whose mind? PloS ONE, 7, e29081.

100Duchaine, B., \& Nakayama, K. (2006). The Cambridge Face Memory Test: Results for neurologically 1001 intact individuals and an investigation of its validity using inverted face stimuli and prosopagnosic 1002 participants. Neuropsychologia, 44, 576-585.

1003ufau, S., Duñabeitia, J. A., Moret-Tatay, C., McGonigal, A., Peeters, D., Alario, F.-X., Balota, D. 1004 A., Brysbaert, M., Carreiras, M., Ferrand, L., Ktori, M., Perea, M., Rastle, K., Sasburg, O., Yap, 1005 M. J., Ziegler, J. C., \& Grainger, J. (2011). Smart phone, smart science: How the use of 1006 smartphones can revolutionize research in cognitive science. PLoS ONE, 6, e24974.

100Timer, M., \& Schlaghecken, F. (1998). Effects of masked stimuli on motor activation: Behavioral and 1008 electrophysiological evidence. Journal of Experimental Psychology: Human Perception and 1009 Performance, 24, 1737-1747 
101(El Emam, K., \& Arbuckle, L. (2013). Anonymizing health data: Case studies and methods to get you 1011 started. Sebastopol, CA: O'Reilly Media.

1012Eriksen, C. W. (1995). The flankers task and response competition: A useful tool for investigating a 1013 variety of cognitive problems. Visual Cognition, 2, 101-118.

1014Eriksson, K., \& Simpson, B. (2010). Emotional reactions to losing explain gender differences in 1015 entering a risky lottery. Judgment and Decision Making, 5, 159-163.

101Æitzgerald, P. J. (2013). Gray colored glasses: Is major depression partially a sensory perceptual 1017 disorder? Journal of Affective Disorders, 151, 418-422.

101\&orster, K. I., \& Forster, J. C. (2003). DMDX: A Windows display program with millisecond 1019 accuracy. Behavior Research Methods, Instruments, \& Computers, 35, 116-124.

1020Garaizar, P., Vadillo, M. A., López-de-Ipiña, D., \& Matute, H. (2014). Measuring software timing 1021 errors in the presentation of visual stimuli in cognitive neuroscience experiments. PLoS ONE, 9 , 1022 e85108.

1023Germine, L., Nakayama, K., Duchaine, B. C., Chabris, C. F., Chatterjee, G., \& Wilmer, J. B. (2012). 1024 Is the Web as good as the lab? Comparable performance from Web and lab in cognitive/perceptual 1025 experiments. Psychonomic Bulletin \& Review, 19, 847-857.

1026itHub issue (2014, October 6). Use requestAnimationFrame when possible to pseudo-sync with 1027 display refresh \#75. Retrieved from https://github.com/jodeleeuw/jsPsych/issues/75/

1028Goodman, J. K., Cryder, C. E., \& Cheema, A. (2013). Data collection in a flat world: The strengths 1029 and weaknesses of Mechanical Turk samples. Journal of Behavioral Decision Making, 26, 2131030224.

1031 Gosling, S. D. \& Mason, W. (2015). Internet research in psychology. Annual Review of Psychology, 1032 66, 877-902.

1033 Haston, S. (2014, April 22). Ultimate slow mo smartphone camera comparison, with fire hand! 1034 Retrieved March 12, 2015, from http://www.mobilegeeks.com/slow-motion-tested-4-top1035 smartphones-fire-hand/ 
1034Hauser, D. J., \& Schwarz, N. (2015). Attentive Turkers: MTurk participants perform better on online 1037 attention checks than do subject pool participants. Behavior Research Methods, 1-8. DOI: 1038 10.3758/s13428-015-0578-z

1039Henrich, J., Heine, S. J., \& Norenzayan, A. (2010). The weirdest people in the world? Behavioral and 1040 Brain Sciences, 33, 61-135.

$104 \mathbb{H}$, C. J., Slivkins, A., Suri, S., \& Vaughan, J. W. (2015, May X). Incentivizing high quality 1042 crowdwork. In Proceedings of the International World Wide Web. Florence, Italy: IW3C2.

104Holmes, N. P., \& Spence, C. (2005). Multisensory integration: Space, time, and superadditivity. 1044 Current Biology, 15, R762-R764.

104Iddemonofelru (2014, May10). Anyone wanna raise awareness of fair pay? [Web blog] Retrieved 1046 from

1047 https://www.reddit.com/r/mturk/comments/257cco/anyone wanna raise awareness of fair pay 1048 I

1049ntons-Peterson, M. J. (1983). Imagery paradigms: How vulnerable are they to experimenters' 1050 expectations? Journal of Experimental Psychology: Human Perception and Performance, 9, 3941051412.

1052peirotis, P. G. (2010). Analyzing the Amazon Mechanical Turk marketplace. XRDS: Crossroads, The 1053 ACM Magazine for Students, 17, 16-21.

1054ames, N., \& Busher, H. (2015). Ethical issues in online research. Educational Research and 1055 Evaluation, 21, 89-94.January 2015 Market Share (2015, January 30). Retrieved February 7, 2015, 1056 from http://www.w3 counter.com/globalstats.php?year=2015\&month=1

105 Kay, P., \& Regier, T. (2003). Resolving the question of color naming universals. Proceedings of the 1058 National Academy of Sciences, 100, 9085-9089.

105Жillingsworth, M. A., \& Gilbert, D. T. (2010). A wandering mind is an unhappy mind. Science, 330, 1060932.

$106 \mathbb{K}$ ing, G. (2011). Ensuring the data-rich future of the social sciences. Science, 331, 719-721.

106Klein, R. A., Ratliff, K. A., Vianello, M., Adams, Jr, R. B., Bahník, Š., Bernstein, M. J., ... \& Nosek, 1063 B.A. (2014). Investigating variation in replicability. Social Psychology, 45, 142-152. 
1064nöferle, K. M., Woods, A., Käppler, F., \& Spence, C. (2015). That sounds sweet: Using crossmodal 1065 correspondences to communicate gustatory attributes. Psychology \& Marketing, 32, 107-120.

1066Krantz, J. H. (2001). Stimulus delivery on the Web: What can be presented when calibration isn't 1067 possible? In U.-D. Reips \& M. Bosnjak (Eds.), Dimensions of internet science (pp. 113-130). 1068 Lengerich, GE: Pabst Science.

106\%raut, R., Olson, J., Banaji, M., Bruckman, A., Cohen, J., \& Couper, M. (2004). Psychological 1070 research online: report of Board of Scientific Affairs' Advisory Group on the Conduct of Research 1071 on the Internet. American psychologist, 59, 105.

107Lakkaraju, K. (2015). A preliminary study of daily sample composition on Amazon Mechanical Turk 1073 (March 11). Available at

1074 SSRN: http://ssrn.com/abstract=2560840 or http://dx.doi.org/10.2139/ssrn.2560840

107§Lease, M., Hullman, J., Bigham, J. P., Bernstein, M. S., Kim, J., Lasecki, W., Bakhshi, S., Mitra, T., $1076 \&$ Miller, R. C. (2013). Mechanical Turk is not anonymous. Available at SSRN 2228728.

1077de Leeuw, J. R. (2014). jsPsych: A JavaScript library for creating behavioral experiments in a Web 1078 browser. Behavior Research Methods, 39, 365-370.

107凡evitan, C. A., Ren, J., Woods, A. T., Boesveldt, S., Chan, J. S., McKenzie, K. J., Dodson, M., Levin, 1080 J. A., Leong, C., \& van den Bosch, J. J. (2014). Cross-cultural color-odor associations. PLoS ONE, 10819 , e101651.

1082 in, K., Chu, D., Mickens, J., Zhuang, L., Zhao, F., \& Qiu, J. (2012, June). Gibraltar: Exposing 1083 hardware devices to web pages using AJAX. In Proceedings of the 3rd USENIX conference on 1084 Web Application Development (p. 7). Boston, MA: USENIX Association.

1085Marder, J. (2015, February 11). The Internet's hidden science factory. Retrieved February 12, 2015, 1086 from http://www.pbs.org/newshour/updates/inside-amazons-hidden-science-factory/

108 Martire, K. A., \& Watkins, I. (2015). Perception problems of the verbal scale: A reanalysis and 1088 application of a membership function approach. Science \& Justice. Available online 28 January 1089 2015, ISSN 1355-0306, http://dx.doi.org/10.1016/j.scijus.2015.01.002.

1090Marx, D. M., \& Goff, P. A. (2005). Clearing the air: The effect of experimenter race on target's test 1091 performance and subjective experience. British Journal of Social Psychology, 44, 645-657. 
1092Mason, W., \& Suri, S. (2012). Conducting behavioral research on Amazon's Mechanical Turk. 1093 Behavior Research Methods, 44, 1-23.

1094Mason, W., \& Watts, D. J. (2010). Financial incentives and the performance of crowds. ACM SigKDD 1095 Explorations Newsletter, 11, 100-108.

1096atthew, D., Krosnick J. A., \& Arthur, L. (2010). Methodology report and user's guide for the 200810972009 ANES Panel Study. Palo Alto, CA and Ann Arbor, MI: Stanford University and the 1098 University of Michigan.

1099McGurk, H., \& MacDonald, J. (1976). Hearing lips and seeing speech. Nature, 264, 746-748.

1100Milland, K. (2014a, January 1). The myth of low cost, high quality on Amazon's Mechanical Turk.

1101 Retrieved March 12, 2015, from http://turkernation.com/showthread.php?21352-The-Myth-of-

1102 Low-Cost-High-Quality-on-Amazon-s-Mechanical-Turk

1103Milland, K. (2014b). Indian Turkers: Shining a spotlight on the invisible masses. Unpublished 1104 manuscript.

1105Miller, G. (2012). The smartphone psychology manifesto. Perspectives on Psychological Science, 7 , $1106 \quad 221-237$.

110TMirams, L., Poliakoff, E., Brown, R. J., \& Lloyd, D. M. (2013). Brief body-scan meditation practice 1108 improves somatosensory perceptual decision making. Consciousness and Cognition, 22, 348-359 1109arayanan, A., \& Shmatikov, V. (2008, May). Robust de-anonymization of large sparse datasets. In 1110 IEEE Symposium on Security and Privacy, 2008 (pp. 111-125). Oakland, CA: IEEE.

$111 \mathbb{N}$ arayanan, A., \& Shmatikov, V. (2009, May). De-anonymizing social networks. In Security and 1112 Privacy, 2009 30th IEEE Symposium (pp. 173-187). Oakland, CA: IEEE.

111Neath, I., Earle, A., Hallett, D., \& Surprenant, A. M. (2011). Response time accuracy in Apple 1114 Macintosh computers. Behavior Research Methods, 43, 353-362.

111 Nicholls, M. E., Loveless, K. M., Thomas, N. A., Loetscher, T., \& Churches, O. (2014). Some 1116 participants may be better than others: Sustained attention and motivation are higher early in 1117 semester. The Quarterly Journal of Experimental Psychology, 68, 1-19. 
1118 Nieuwenhuis, S., Stins, J. F., Posthuma, D., Polderman, T. J., Boomsma, D. I., \& de Geus, E. J. (2006). 1119 Accounting for sequential trial effects in the flanker task: Conflict adaptation or associative 1120 priming? Memory \& Cognition, 34, 1260-1272.

$112 \mathbb{N i j h o l t , ~ A . ~ ( 2 0 1 4 ) . ~ B r e a k i n g ~ f r e s h ~ g r o u n d ~ i n ~ h u m a n - m e d i a ~ i n t e r a c t i o n ~ r e s e a r c h . ~ F r o n t i e r s ~ i n ~ I C T , ~} \mathbf{1}$, 11224.

112Nosofsky, R. M., Gluck, M. A., Palmeri, T. J., McKinley, S. C., \& Glauthier, P. (1994). Comparing 1124 modes of rule-based classification learning: A replication and extension of Shepard, Hovland, and 1125 Jenkins (1961). Memory \& Cognition, 22, 352-369.

1126ppenheimer, D. M., Meyvis, T., \& Davidenko, N. (2009). Instructional manipulation checks: 1127 Detecting satisficing to increase statistical power. Journal of Experimental Social Psychology, 45, $1128 \quad 867-872$.

11290rne, M. T. (1962). On the social psychology of the psychological experiment: With particular 1130 reference to demand characteristics and their implications. American Psychologist, 17, 776-783.

113 Paolacci, G., \& Chandler, J. (2014). Inside the Turk: Understanding Mechanical Turk as a participant 1132 pool. Current Directions in Psychological Science, 23, 184-188.

1133Paolacci, G., Chandler, J., \& Ipeirotis, P. G. (2010). Running experiments on Amazon Mechanical 1134 Turk. Judgment and Decision Making, 5, 411-419.

113Paredes-Valverde, M. A., Alor-Hernández, G., Rodríguez-González, A., Valencia-García, R., \& 1136 Jiménez-Domingo, E. (2015). A systematic review of tools, languages, and methodologies for 1137 mashup development. Software: Practice and Experience, 45, 365-397.

113\$echey, R., Attwood, A., Munafò, M., Scott-Samuel, N. E., Woods, A., \& Marteau, T. M. (in prep). 1139 Wine glass size and shape impact on judgements of volume.

114Peer, E., Samat, S., Brandimarte, L. \& Acquisti, A. (2015). Beyond the Turk: An empirical comparison 1141 of alternative platforms for crowdsourcing online behavioral research. Available online 14 April 1142 2015, http://dx.doi.org/10.2139/ssrn.2594183.

114Peromaa, T. (2015). Colors of "The Dress" (original \& red-green versions): Percepts of 884 readers. 1144 Retrieved March 7, 2015, from http://tperomaa.vapaavuoro.uusisuomi.fi/kulttuuri/189048-colors1145 of-“the-dress"-original-red-green-versions-percepts-of-884-readers 
114Pew Research Center (2015, Jan). Public and scientists' views on science and society. Retrieved from 1147 http://www.pewinternet.org/files/2015/01/PI ScienceandSociety Report 012915.pdf

1148iqueras-Fiszman, B., Velasco, C., \& Spence, C. (2012). Exploring implicit and explicit crossmodal 1149 colour-flavour correspondences in product packaging. Food Quality and Preference, 25, 148-155.

115(Plant, R. R., \& Turner, G. (2009). Millisecond precision psychological research in a world of 1151 commodity computers: New hardware, new problems? Behavior Research Methods, 41, 598-614.

115Poerio, G. L., Totterdell, P., \& Miles, E. (2013). Mind-wandering and negative mood: Does one thing 1153 really lead to another? Consciousness and Cognition, 22, 1412-1421.

1154Reimers, S., \& Stewart, N. (2014). Presentation and response timing accuracy in Adobe Flash and 1155 HTML5/JavaScript Web experiments. Behavior Research Methods, doi:10.3758/s13428-014$1156 \quad 0471-1$.

115Ross, M. W. (2014). Do research ethics need updating for the digital age? Monitor on Psychology, 45, 115864.

115Rumenik, D. K., Capasso, D. R., \& Hendrick, C. (1977). Experimenter sex effects in behavioral 1160 research. Psychological Bulletin, 84, 852.

116 ISchubert, T. W., Murteira, C., Collins, E. C., \& Lopes, D. (2013). ScriptingRT: A software library for 1162 collecting response latencies in online studies of cognition. PLoS ONE, 8, e67769.

11635 earles, K., \& Ryan, J. (2015, May 4). Researchers are rushing to Amazon's Mechanical Turk. Should 1164 they? Retrieved May 5, 2015, from http://www.washingtonpost.com/blogs/monkey1165 cage/wp/2015/05/04/researchers-are-rushing-to-amazons-mechanical-turk-should-they/

116\$hams, L., Kamitani, Y., \& Shimojo, S. (2002). Visual illusion induced by sound. Cognitive Brain 1167 Research, 14, 147-152.

1168Shapiro, K. L., Raymond, J. E., \& Arnell, K. M. (1997). The attentional blink. Trends in Cognitive 1169 Sciences, 1, 291-296.

1170Sheehan, K. (2015, April 17). How many HITs are academic HITs? My data part 1. Retrieved May 1171 5, 2015, from https://mturk4academics.wordpress.com/2015/04/17/how-many-hits-are-academic-

1172 hits-my-data-part-1/Shepard, R. N., Hovland, C. I., \& Jenkins, H. M. (1961). Learning and 1173 memorization of classifications. Psychological Monographs: General and Applied, 75, 1-42. 
1174Shermer, D. Z., \& Levitan, C. A. (2014). Red hot: The crossmodal effect of color intensity on 1175 piquancy. Multisensory Research, 27, 207-223.

117 \$ilberman, S., Milland, K., LaPlante, R., Ross, J., \& Irani, L. (2015, March 16). Stop citing Ross et 1177 al. 2010. Retrieved March 22, 2015, from https://medium.com/@silberman/stop-citing-ross-et-al1178 2010-who-are-the-crowdworkers-b3b9b1e8d300

1179Simcox, T., \& Fiez, J. A. (2014). Collecting response times using Amazon Mechanical Turk and 1180 Adobe Flash. Behavior Research Methods, 46, 95-111.

118 Simonsohn, U., Nelson, L. D., \& Simmons, J. P. (2014). P-curve: A key to the file-drawer. Journal of 1182 Experimental Psychology: General, 143, 534-547.

1183Source-to-source compiler. (n.d.). Wikipedia. Retrieved February 13, 2015, from 1184 https://en.wikipedia.org/wiki/Source-to-source_compiler Spence, C. (2007). Audiovisual 1185 multisensory

1186 integration. Acoustical Science \& Technology, 28, 61-70.

118 Spellman, B. A. (2012). Introduction to the special section data, data, everywhere... especially in my 1188 file drawer. Perspectives on Psychological Science, 7, 58-59.

118 Stafford, T., \& Dewar, M. (2014). Tracing the trajectory of skill learning with a very large sample of 1190 online game players. Psychological Science, 25, 511-518.

1191Stapleton, J., Woods, A. T., Casey, S., \& Newell, F. N. (submitted). The contribution of facial and 1192 vocal cues on the perceived attractiveness of others: A role for visual 'capture'. PLoS ONE.

11935 tewart, N., Ungemach, C., Harris, A. J. L., Bartels, D. M., \& Newell, B. R. (submitted). The size of 1194 the active Amazon Mechanical Turk population. Judgment and Decision Making.

1195Thompson, S. (1996). Internet connectivity: addiction and dependency study (Doctoral dissertation). 1196 Retrieved from http://www.academia.edu/download/30519620/Thompson_-_IADS.pdf

1197To, L., Woods, R. L., Goldstein, R. B., \& Peli, E. (2013). Psychophysical contrast calibration. Vision 1198 Research, 90, 15-24.

1199 Velasco, C., Wan, X., Knoeferle, K., Zhou, X., Salgado-Montejo, A., \& Spence, C. (2015b). Searching 1200 for flavor labels in food products: The influence of color-flavor congruence and association 1201 strength. Frontiers in Psychology, 6:301. 
1202 elasco, C., Wan, X., Salgado-Montejo, A., Woods, A., Onate, G., Mi, B., \& Spence, C. (2014). The 1203 context of colour-flavour associations in crisps packaging: A cross-cultural study comparing 1204 Chinese, Colombian, and British consumers. Food Quality and Preference, 38, 49-57.

1205 Velasco, C., Woods, A. T., Deroy, O., \& Spence, C. (2015a). Hedonic mediation of the crossmodal 1206 correspondence between taste and shape. Food Quality and Preference, 41, 151-158.

120 Nelasco, C., Woods, A., Liu, J., \& Spence, C. (in press). Assessing the role of taste intensity and 1208 hedonics in taste/shape correspondences. Multisensory Research. DOI: 10.1163/22134808120900002489.

1210Wan, X., Velasco, C., Michel, C., Mu, B., Woods, A. T., \& Spence, C. (2014a). Does the shape of the 1211 glass influence the crossmodal association between colour and flavour? A cross-cultural 1212 comparison. Flavour, $3,3$.

1213Wan, X., Woods, A. T., Seoul, K.-H., Butcher, N., \& Spence, C. (2015). When the shape of the glass

1214 influences the flavour associated with a coloured beverage: Evidence from consumers in three 1215 countries. Food Quality \& Preference, 39, 109-116.

1216 Wan, X., Woods, A. T., van den Bosch, J., McKenzie, K. J., Velasco, C., \& Spence, C. (2014b). Cross-

1217 cultural differences in crossmodal correspondences between tastes and visual features. Frontiers 1218 in Psychology: Cognition, 5:1365.

1219echsler, D. (2008). Wechsler adult intelligence scale-Fourth Edition (WAIS-IV). San Antonio, TX: 1220 NCS Pearson.

122 Wilson, R. E., Gosling, S. D., \& Graham, L. T. (2012). A review of Facebook research in the social 1222 sciences. Perspectives on Psychological Science, 7, 203-220.

1223Witzel, J., Cornelius, S., Witzel, N., Forster, K. I., \& Forster, J. C. (2013). Testing the viability of 1224 webDMDX for masked priming experiments. The Mental Lexicon, 8, 421-449.

1225Woods, A. T., Levitan, C.A., Butcher, N., \& Spence, C. (2015).Bouba Kiki et al over several samples 1226 from different populations. Figshare http://dx.doi.org/10.6084/m9.figshare.1408803 Retrieved 1227 18:52, May 09, 2015 (GMT) 
1228Woods, A. T., Spence, C., Butcher, N., \& Deroy, O. (2013). Fast lemons and sour boulders: Testing 1229 the semantic hypothesis of crossmodal correspondences using an internet-based testing 1230 methodology. i-Perception, 4, 365-369.

123 YYung, A., Cardoso-Leite, P., Dale, G., Bavelier, D., \& Green, C. S. (2015). Methods to test visual 1232 attention online. Journal of Visualized Experiments, 96, e52470. 


\section{1}

Articles per year found on the Web of Science prior to 2015.

The number of articles found on the Web of Science prior to 2015 with the search term 'Mechanical Turk' within the 'psychology' research area (search conducted on 12-03-2015).

100

80

60

है

40

20

0

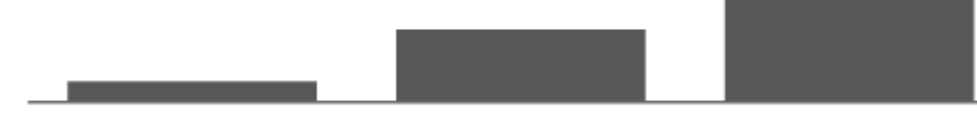

2010

2011

2012

2013

2014

Year 
2

The distribution of ages for US and Indian Mechanical Turk participants.

The distribution of ages for US and Indian participants recruited via Mechanical Turk or tested in a lab-based setting in the USA and India (Woods et al., in prep).

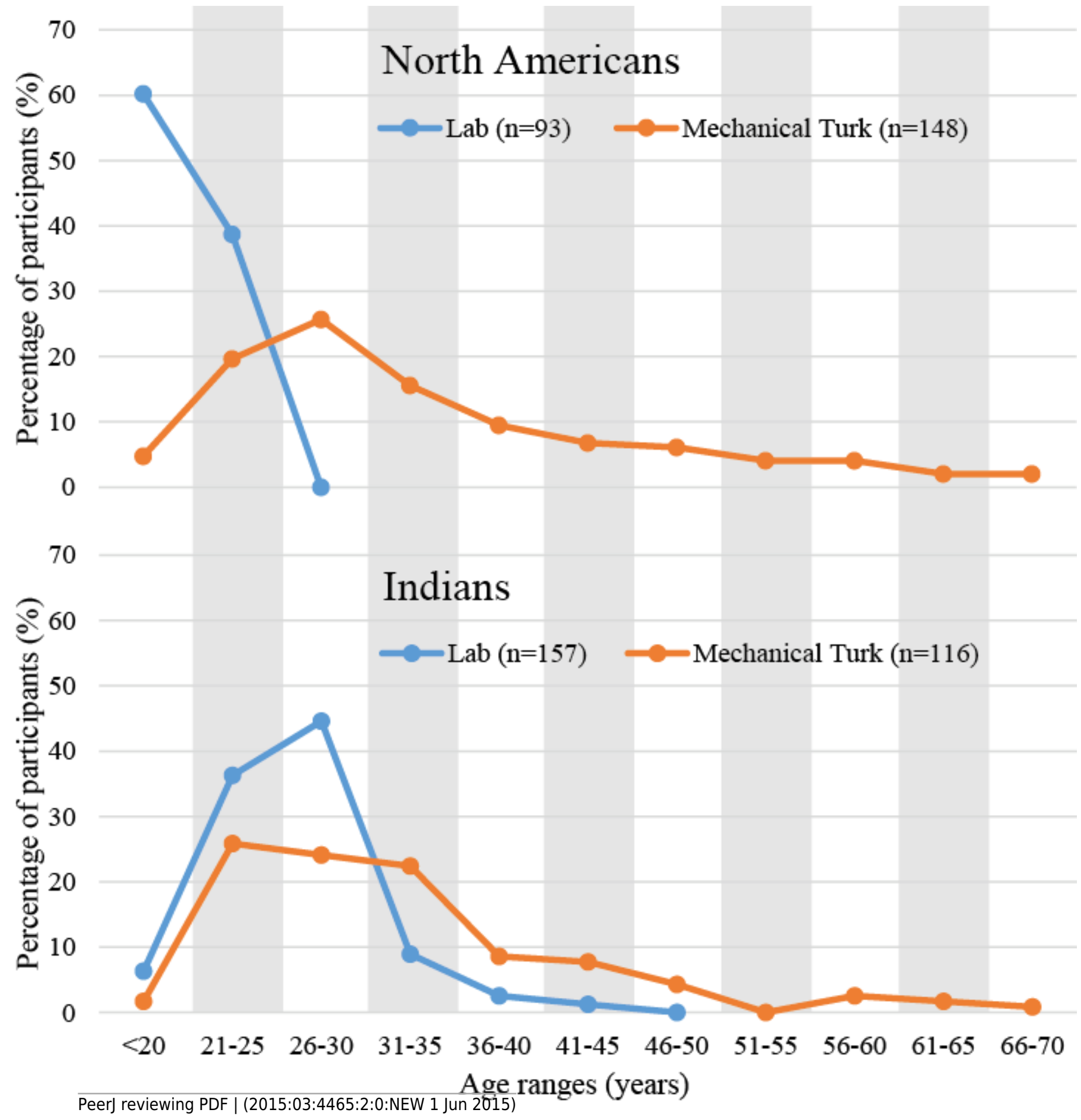




\section{3}

The rate of experiment completion over a four-hour period.

The rate of experiment completion over a four-hour period ( $n=360$; collected February, 2015, from $8 \mathrm{pm}$ onward, Eastern Standard Time; Pechey et al., in prep). The first author's suspicion is that 'long tail' sign-ups typically observed in MTurk are the result of some participants signing up and then quitting a study, and the resultant 'time-out' delay before a new person can take the unfinished slot.

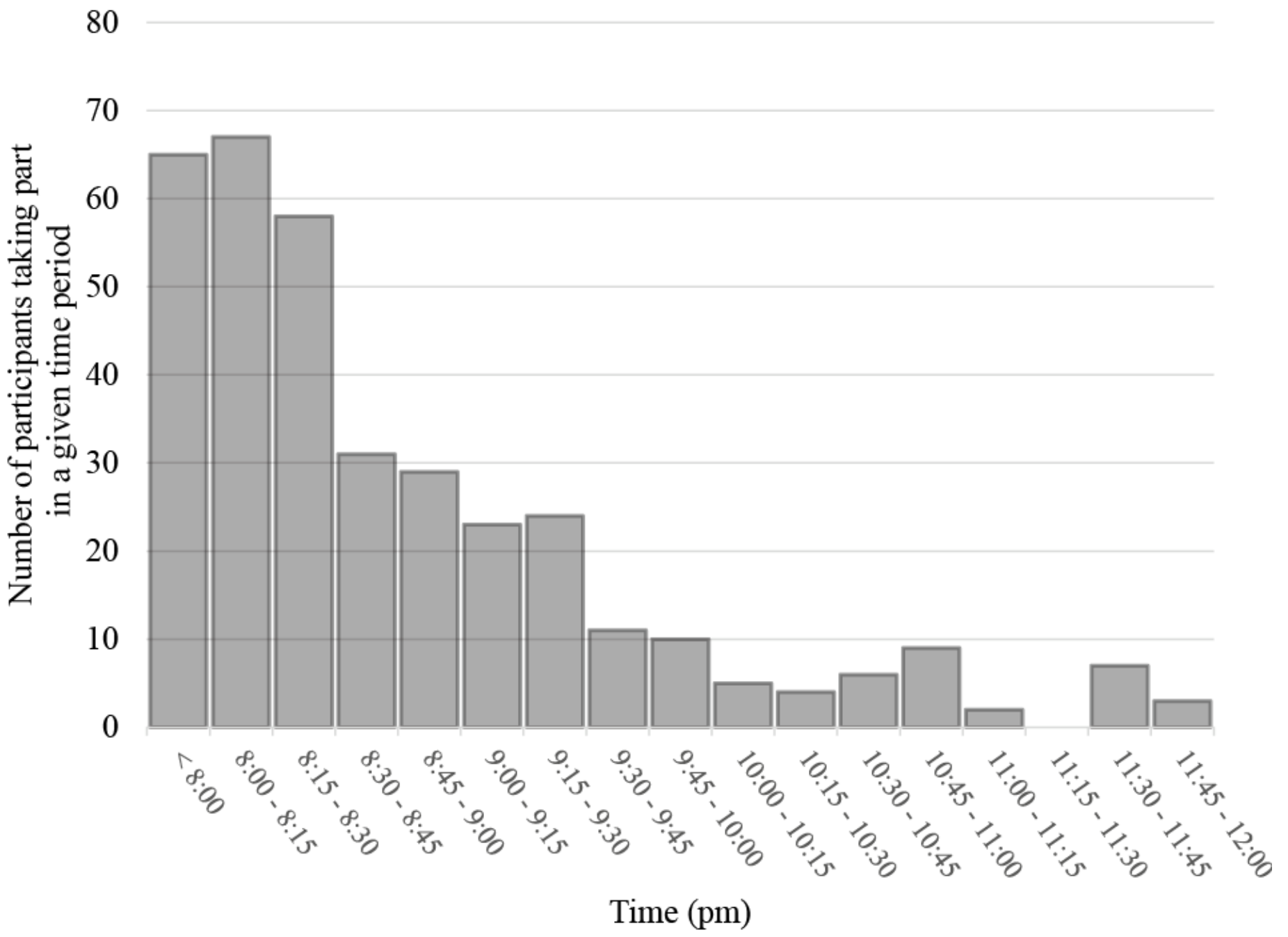


4

An example TurkOpticon requester profile.

An example TurkOpticon requester profile (74 MTurkers having provided feedback on the requester).

\begin{tabular}{llcc} 
AMT Requester Name \& ID $\boldsymbol{\Delta} \boldsymbol{\nabla}$ & \multicolumn{2}{l}{ Ratings [ ] (averaged) $\boldsymbol{\Delta}$} & \# of Reports $\boldsymbol{\Delta} \boldsymbol{\nabla}$ \\
\hline Andy Woods & PAY: & $4.55 / 5$ & 74 \\
A1F33MP8XRWBHE & FAST: & $4.87 / 5$ & \\
HIT Group » & FAIR: & $40 / 5$ \\
& COMM: & $4.72 / 5$ \\
\hline
\end{tabular}




\section{5}

Likelihood of stimuli of different presentation durations appearing on screen.

Likelihood of stimuli of different presentation durations appearing on screen, or doing so with the wrong start time, end time, and/or duration (screen refresh of 16.67).

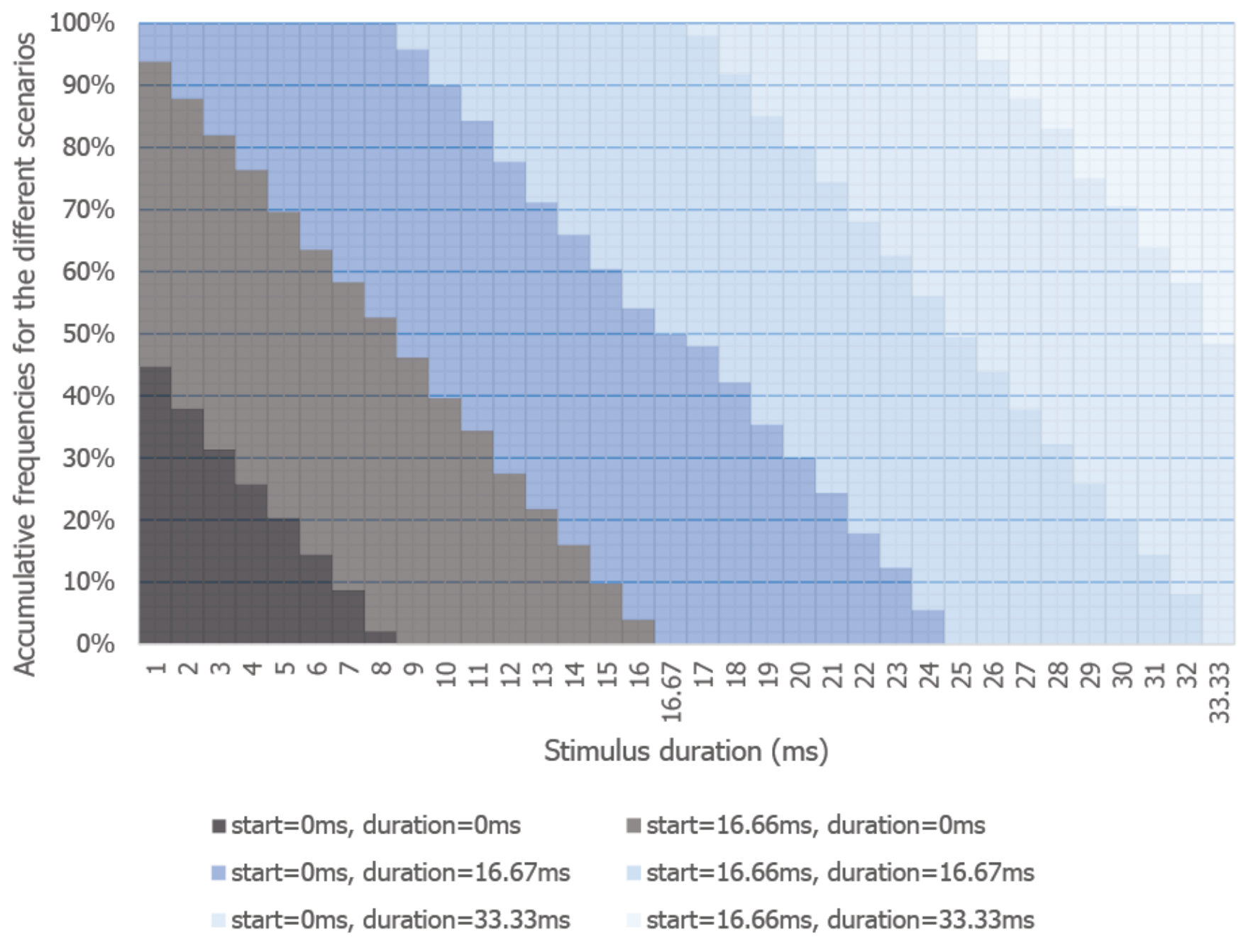




\section{Table $\mathbf{1}_{\text {(on next page) }}$}

Popular recruitment platforms and some of their characteristics.

Popular recruitment platforms and some of their characteristics. *Note that some MTurkers have a 'Masters' performance-based qualification (see https://www.reddit.com/r/mturk/comments/1qmaqc/how_do_i_earn_masters_qualification/). MTurk charges researchers 20\% of their participant fees for recruiting from this Masters group. Be wary that when creating a task for MTurkers to do using Amazon's own 'web interface' creation tool, 'Masters' is set as the default group from which you wish to recruit. 


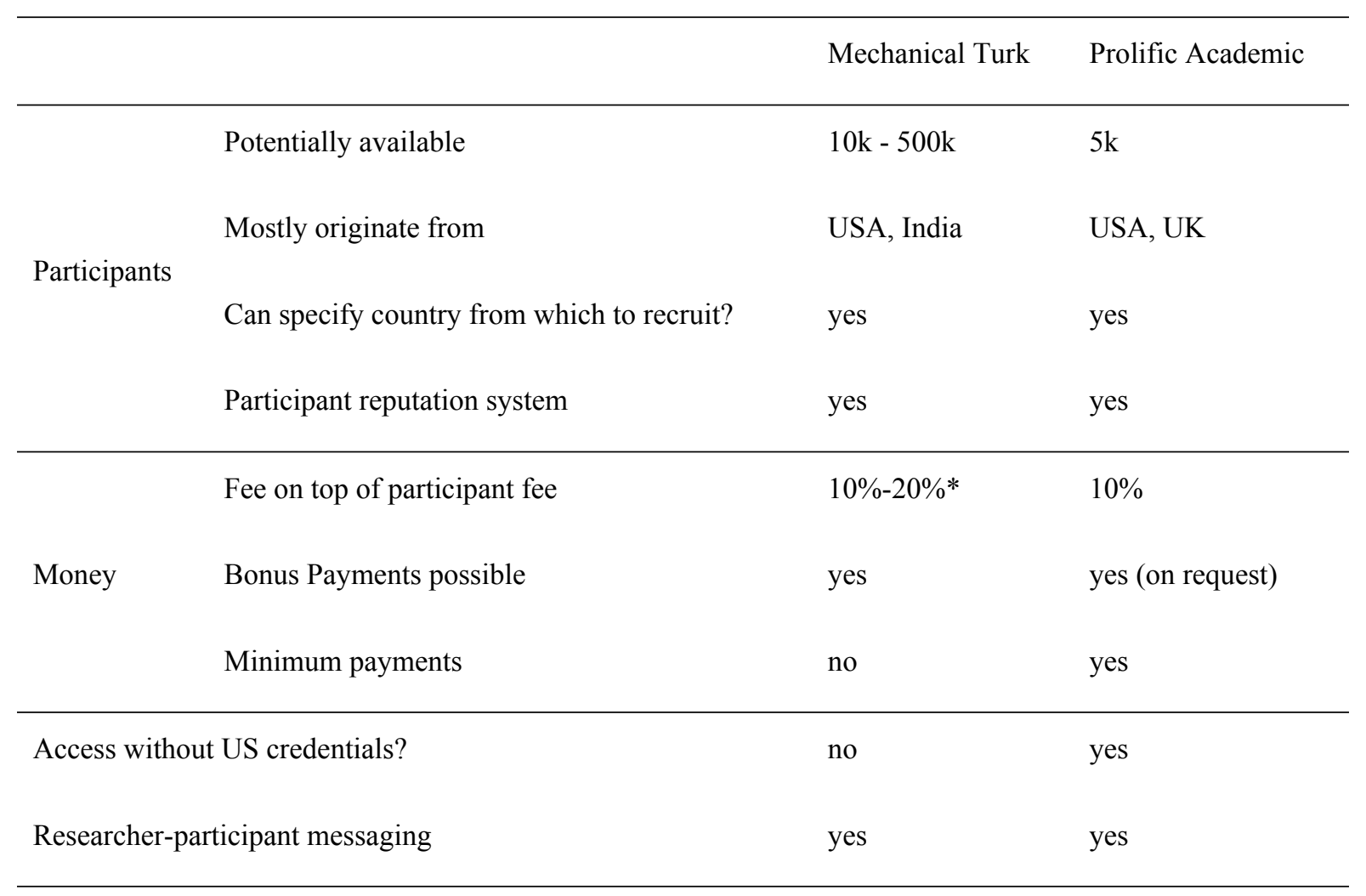


Table 2 (on next page)

Age and sex characteristics of 4 recent large internet- and phone-based sample studies.

Age and sex characteristics of 4 recent large internet- and phone-based sample studies. Note that $12.5 \%$ of Mason and Suri's (2012) participants did not report their gender. 
2 Table 2: Age and sex characteristics of 4 recent large internet-and phone-based sample studies.

3 Note that 12.5\% of Mason and Suri's (2012) participants did not report their gender.

\begin{tabular}{|c|c|c|c|c|c|}
\hline & $\begin{array}{c}\text { Recruitment } \\
\text { platform }\end{array}$ & Sample & $\mathrm{n}$ & $\begin{array}{c}\% \\
\text { female }\end{array}$ & $\begin{array}{l}\text { Average } \\
\text { age (SD) }\end{array}$ \\
\hline Shermer \& Levitan (2014) & MTurk & US & 2737 & $40 \%$ & $29.9(9.6)$ \\
\hline Germine et al. (2012) & TextMyBrain & World & $\begin{array}{c}4080 \\
\text { (study 1) }\end{array}$ & $65 \%$ & $26(11)$ \\
\hline Mason \& Suri (2012) & MTurk & World & $\begin{array}{c}2896 \\
\text { (5 studies) }\end{array}$ & $55 \%$ & 32 \\
\hline Buhrmester et al. (2011) & MTurk & World & 3006 & $55 \%$ & $32.8(11.5)$ \\
\hline
\end{tabular}




\section{Table 3 (on next page)}

Popular online research platforms, their main features, strengths and weaknesses, as reported by their developers.

Popular online research platforms, their main features, strengths and weaknesses, as reported by their developers (survey conducted through Google Forms, on 13-3-2015, which is not listed in the below table on account of being mostly questionnaire-focused and thus 'neutral territory' for responders; *suffixed rows requested by reviewer / data not provided by developers). 


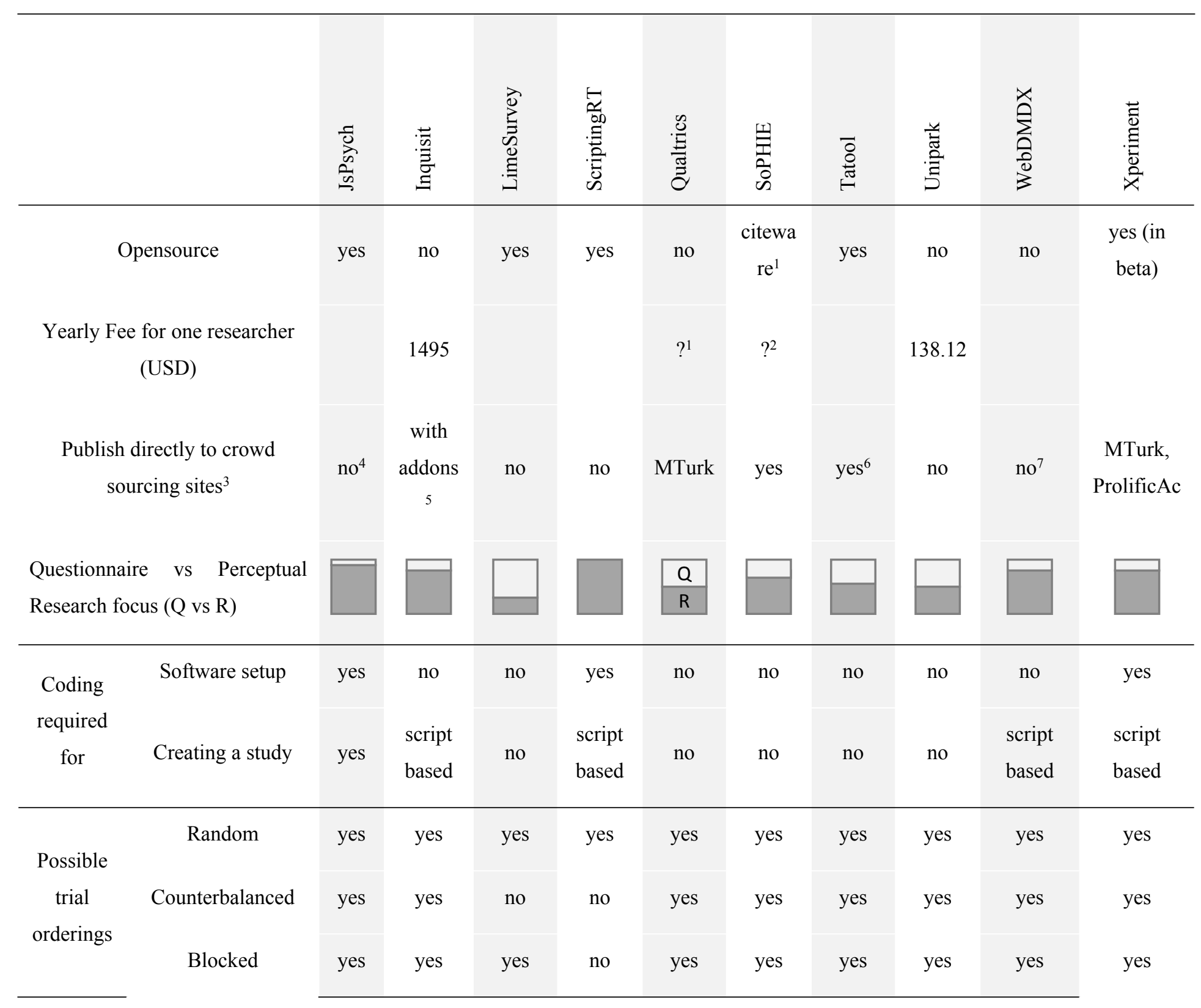




\begin{tabular}{|c|c|c|c|c|c|c|c|c|c|c|}
\hline Reaction times measurable in* & $\mathrm{ms}$ & $\mathrm{ms}^{8}$ & $\mathrm{~ms}^{9}$ & $\mathrm{~ms}$ & $\mathrm{~ms}$ & $\mathrm{~ms}$ & $\mathrm{~ms}$ & $\mathrm{~ms}$ & $\mathrm{~ms}^{8}$ & $\mathrm{~ms}$ \\
\hline Image, sound \& video stimuli* & yes & yes & yes & yes & yes & yes & yes & yes & yes & yes \\
\hline
\end{tabular}

2 1. Many academic institutions have licenses with Qualtrics already. Individual academic pricing was not disclosed to us and could not be found via search engines. Note also that some features (e.g., more advanced randomization) may require a more expensive package.

4 2. "Free as CiteWare, Commercial Hosting Service from SoPHIE Labs (950 USD / year)"

5 3. Although all platforms let the researcher provide a URL where the participant can undertake a study, some crowd-sourcing sites need to communicate directly with the testing software in order to know, for example, whether the participant should be paid.

7 4. "None directly; but it can be used to publish on any platform that allows for custom JavaScript and HTML content"

8 5. See http://www.millisecond.com/support/docs/v4/html/howto/interopsurveys.htm

9 6. "Any crowd sourcing site that allows an external link to Tatool to run an experiment (no login required)"

10 7. "It uses an HTML POST command so pretty much anything, depends how skilled you are. We provide a site running a general purpose script to gather data and email it to experimenters should people not be in a position to setup a site to gather the data."

12 8. As discussed in the text, both these packages run outside of the browser and thus likely to more reliably and more accurately measure reaction time.

13 9. This was a topic of contention amongst our reviewers. However, as LimeSurvey is quite extendable with packages such as http://www.w3.org/TR/hr-time/, timing accuracy within this framework is quite on par with other browser based frameworks. 